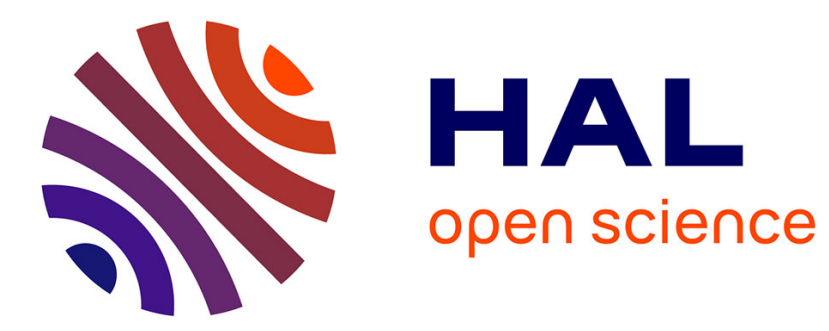

\title{
Governance structure, technical change and industry competition
}

Mattia Guerini, Philipp Harting, Mauro Napoletano

\section{To cite this version:}

Mattia Guerini, Philipp Harting, Mauro Napoletano. Governance structure, technical change and industry competition. 2020. hal-03374377

\section{HAL Id: hal-03374377 \\ https://hal-sciencespo.archives-ouvertes.fr/hal-03374377}

Preprint submitted on 12 Oct 2021

HAL is a multi-disciplinary open access archive for the deposit and dissemination of scientific research documents, whether they are published or not. The documents may come from teaching and research institutions in France or abroad, or from public or private research centers.
L'archive ouverte pluridisciplinaire HAL, est destinée au dépôt et à la diffusion de documents scientifiques de niveau recherche, publiés ou non, émanant des établissements d'enseignement et de recherche français ou étrangers, des laboratoires publics ou privés. 


\section{SciencesPo}

GOVERNANCE STRUCTURE, TECHNICAL CHANGE AND INDUSTRY COMPETITION

Mattia Guerini

Philipp Harting

Mauro Napoletano 


\section{ofce}

\section{SciencesPo}

EDITORIAL BOARD

Chair: Xavier Ragot (Sciences Po, OFCE)

Members: Jérôme Creel (Sciences Po, OFCE), Eric Heyer (Sciences Po, OFCE), Sarah Guillou (Sciences Po, OFCE), Xavier Timbeau (Sciences Po, OFCE)

\section{CONTACT US}

OFCE

10 place de Catalogne | 75014 Paris | France

Tél. +33144185424

www.ofce.fr

This Working Paper:

Mattia Guerini, Philipp Harting and Mauro Napoletano

Governance structure, technical change and industry competition

Sciences Po OFCE Working Paper, n² 29/2020.

Downloaded from URL: www.ofce.sciences-po.fr/pdf/dtravail/WP2020-29.pdf

DOI - ISSN 
ABOUT THE AUTHORS

Mattia Guerini: GREDEG, CNRS, Université Côte d'Azur, OFCE-Sciences Po et Institute of Economics, Scuola Superiore "Sant'Anna"

Email Address: mattia.guerini@sciencespo.fr

Philipp Harting: Bielefeld University,

Email Address: philipp.harting@uni-bielefeld.de

Mauro Napoletano, GREDEG, CNRS, Université Côte d'Azur, Sciences Po, OFCE, France, SKEMA Business School, Institute of Economics, Scuola Superiore "Sant'Anna"

Email Address: mauro.napoletano@sciencespo.fr

\begin{abstract}
We develop a model to study the impact of corporate governance on firm investment decisions and industry competition. In the model, governance structure affects the distribution of shares among short- and long-term oriented investors, the robustness of the management regarding pos- sible stockholder interference, and the managerial remuneration scheme. A bargaining process between firm's stakeholders determines the optimal allocation of financial resources between real investments in R\&D and financial investments in shares buybacks. We characterize the relation between corporate governance and firm's optimal investment strategy and we study how different governance structures shape technical progress and the degree of competition over the industrial life cycle. Numerical simulations of a calibrated set-up of the model show that pooling together industries characterized by heterogeneous governance structures generate the welldocumented inverted-U shaped relation between competition and innovation.
\end{abstract}

\title{
KEYWORDS
}

Governance structure, industry dynamics, competition, technical change.

JEL

G34, L22, M12. 



\title{
Governance structure, technical change and industry competition
}

\author{
Mattia Guerini ${ }^{1,3,5} \quad$ Philipp Harting ${ }^{* 2} \quad$ Mauro Napoletano ${ }^{1,3,4,5}$ \\ ${ }^{1}$ GREDEG, CNRS, Université Côte d'Azur \\ ${ }^{2}$ Bielefeld University \\ ${ }^{3}$ Sciences Po, OFCE, France \\ ${ }^{4}$ SKEMA Business School \\ ${ }^{5}$ Institute of Economics, Scuola Superiore "Sant'Anna"
}

November 23, 2020

\begin{abstract}
We develop a model to study the impact of corporate governance on firm investment decisions and industry competition. In the model, governance structure affects the distribution of shares among short- and long-term oriented investors, the robustness of the management regarding possible stockholder interference, and the managerial remuneration scheme. A bargaining process between firm's stakeholders determines the optimal allocation of financial resources between real investments in $R \& D$ and financial investments in shares buybacks. We characterize the relation between corporate governance and firm's optimal investment strategy and we study how different governance structures shape technical progress and the degree of competition over the industrial life cycle. Numerical simulations of a calibrated set-up of the model show that pooling together industries characterized by heterogeneous governance structures generate the well-documented inverted-U shaped relation between competition and innovation.
\end{abstract}

JEL Codes: G34, L22, M12.

Keywords: governance structure, industry dynamics, competition, technical change.

\section{Introduction}

Recent empirical evidence indicates the existence of an inverted-U shaped relation between innovation and competition (see, e.g., Aghion et al., 2005). ${ }^{1}$ This relationship is mediated by a variety of factors. One of them is corporate governance meant as "the collection of mechanisms, processes and relations by which corporations are controlled and operated" (see Shailer, 2004).

Several studies have shown how different aspects of corporate governance may impact on firm innovation. One of them is the ownership structure of firms (e.g. Kim et al., 2008). Another one

\footnotetext{
${ }^{*}$ Corresponding Author: Chair for Economic Theory and Computational Economics (ETACE), Dept. of Business Administration and Economics, Bielefeld University. Postal address: Postbox 1001 31, D-33501, Bielefeld, Germany. E-mail: pharting@wiwi.uni-bielefeld.de.

${ }^{1}$ Early empirical support for this hypothesis has been provided by, Scherer (1967) and Levin et al. (1985). More recent empirical evidence confirms that an inverted-U shaped relation is the most appropriate one for explaining the link between market structure and technical progress. Most prominently, Aghion et al. (2005) find strong evidence for an inverted-U shaped relationship using panel data of different UK industries and explain this non-monotonicity by a theoretical model that reconciles Schumpeterian and Arrowian views. The results by Aghion et al. (2005) have been then corroborated by other empirical studies (see, e.g., Tingvall and Poldahl, 2006; Kilponen and Santavirta, 2007; Polder and Veldhuizen, 2012; Askenazy et al., 2013; Peneder and Wörter, 2014).
} 
is the presence of institutional investors and career concerns of managers (e.g. Aghion et al., 2013; Chakravarty and Grewal, 2011). A third aspect is represented by the financial performance-based remuneration system for managers (e.g. Honoré et al., 2015). At the same time, those studies have not formulated a comprehensive theory describing how the interaction among different aspects of corporate governance may influence innovation by heterogeneous firms, and how the latter may in turn shape the process of competition within an industry. This is the main task we try to accomplish in this paper.

We develop a formal model that explains how several aspects of governance structure of a publicly traded firm interact in determining firm's decision about the allocation of funds either to a productivity-enhancing $R \& D$ investment or to an investment in share buybacks. On the one hand, $R \& D$ investments increase a firm's productivity and competitiveness in the industry. They can therefore generate higher profits and thus increase dividends and managers' bonuses. On the other hand, share buybacks increase a firm's share price. They thus have an immediate impact on shareholders' wealth and on the value of managers' share-based remuneration. In the model, we assume that managers and shareholders are the relevant stakeholders for a firm's investment decision. In addition, shareholders are divided in two different groups according to their investment horizon: short- or long-term investors. The three stakeholders participate to a tripartite bargaining process that determines firm's optimal allocation of internal funds between $R \& D$ investments and shares buybacks. Corporate governance structure, in this context, encompasses the distribution of bargaining power among investors and the management, as well as the managerial remuneration scheme composed of bonus- and equity-based elements. The bargaining power of each stakeholder is determined by the distribution of shares among the short- and long-term oriented investors, and by the robustness of the management regarding possible interference of shareholders.

We first characterize the impact of governance structure on the investment behaviour of a single firm by employing a static and deterministic version of the model. We show that a stronger presence of short-term investors, and/or a higher share-based compensation of managers crowds out R\&D investments in favour of buybacks. Although the static model already provides insights on how corporate governance impacts on innovation, it cannot be used to study how the latter may alter the process of competition among heterogeneous firms and the dynamics of an industry. For this reason, we consider a dynamic and stochastic version of the model that allows us to study the effects of governance structure upon technical change and competition over the industry life cycle (Klepper, 1996). Simulations using a calibrated set-up of this extended version of the model demonstrate the existence of non-trivial relationships between governance structure and industry dynamics. While technical progress is positively associated with the presence of long-term investors, the link between market concentration and ownership structure is multifaceted. The relation can either be monotonically decreasing or inverted-U shaped, depending on (i) the managerial independence, (ii) the stage of the industry life-cycle, and (iii) the short- or long-term orientation of managers induced by their payment scheme.

In a final step, we aggregate the simulation results over all the considered configurations of governance structure and over different phases of the industry life-cycle. By considering the emergent level of industry competition and the rate of technical change at once, we find that they form an inverted-U shaped relationship. This last finding provides a complementary view on the link between technical change and competition (see Aghion et al., 2005). In particular, it indicates that this relation is affected by the characteristics of the corporate governance, and it is different across indus- 
try life-cycle stages.

The paper is organized as follows. In Section 2, we provide a short review of the relevant literature about corporate governance and firm innovation and we list two stylized facts about governance structure and innovation that our paper tries to address. Section 3 introduces the static model of corporate governance and formally describes the effects of governance structure on the optimal allocation of resources. Section 4 and Section 5 respectively describe the dynamic industry model and its calibration. The results of extensive simulation experiments addressing the effect of governance structure on competition and technical progress are discussed in Section 6. Section 7 provides conclusive remarks. Complementary technical details can be found in the Appendix.

\section{Governance structure and firm innovation: two stylized facts}

The past decades have witnessed a growing influence of institutional investors in publicly owned companies. Their participation in the U.S. stock market (measured by the percentage of total ownership of shares) has been increasing from 10\% in 1952 to over 70\% in 2006 (see Gillan and Starks, 2007). Institutional investors have also played a far more active role in the firms' key decisions, e.g. by installing representatives in corporate boards, or by executing their voting rights as block-holders. The increasing importance of institutional investors has transformed the governance landscape of the firm, exacerbating conflicts between shareholders and management.

Questions on whether a larger presence of institutional investors has a positive or negative effect on innovation have originated a large debate both among academics and practitioners. For instance, Aghion et al. (2013) analyse the link between institutional ownership and innovation activities and find a positive relationship, due to career concerns of managers under institutional ownership. Other studies (e.g. Sherman et al., 1998) highlight instead that the effect of institutional ownership on firm innovation is very much affected by the degree of investors' heterogeneity. Investors' heterogeneity might indeed be the source of conflicting interests not only between shareholders and the management (a classical principal-agent conflict, see e.g., Jensen and Meckling, 1976) but also among different types of shareholders (a principal-principal conflict; see, e.g., Young et al., 2008). The literature has also focused on the distinction between short- and long-term institutional investors (e.g. Gaspar et al., 2012). In this context, Bushee (1998) finds that managers are more likely to cut R\&D expenses if a higher proportion of short-term shareholders is present. In addition, Brossard et al. (2013) show that the presence of institutional investors promotes R\&D investments as long as impatient investors are not dominating. Similarly, Cremers et al. (2020) provide evidence that the presence of short-term institutional investors is associated with cuts to R\&D investments in order to generate higher earnings and temporary boosts in the stock price. The evidence provided by the above studies leads us to state the first stylized fact:

SF1 A strong presence of impatient (short-term) investors among the shareholders of a firm has a negative effect on firm RED activities.

The debate about the impact of institutional ownership on innovation is very much linked to the one about managers' incentives over alternative investments. In the last decades, non-financial corporations started to reallocate an increasing amount of resources from their core business activities (included R\&D) towards alternative financial investments of different kinds (Epstein, 2005). In this context, programs to repurchase own stocks have gained massive relevance for publicly listed 
firms. Lazonick (2014) reports that between 2003 and 2012, S\&P 500 companies, invested 54\% of their earnings into share repurchases. Large European firms are following this trend. S\&P 350 Europe companies have allocated $20 \%$ of total earnings toward share buybacks in the 2000-2015 period (see Sakinc, 2017). Some economists have expressed concerns that the rising frequency and volume of stock repurchase programs might have crowding-out effects, leading to underinvestment in longterm and intangible projects such as R\&D (see, e.g., Lazonick and O'Sullivan, 2000; Lazonick, 2014).

The traditional view suggests that buybacks are used as a signalling device (e.g. Comment and Jarrell, 1991), to take advantage of a potential undervaluation of firms' stocks (e.g. Ikenberry et al., 1995) or as a channel to distribute excess capital to shareholders (e.g. Dittmar, 2000). Bens et al. (2002) connects share repurchases with the compensation scheme of executives estimating that firms experiencing a significant exercise of employee stock options shift resources away from real investments towards the repurchase of their own stocks. ${ }^{2}$ More recent empirical evidence supports this finding. Using a sample of 700 US firms, Bhargava (2013) shows that share repurchases are positively associated with the amount of stock options granted by the firms as part of their executive compensation schemes. Furthermore, share repurchases and stock options are negatively associated with expenditures on research and development supporting the crowding-out hypothesis. Similarly, Turco (2018) finds a positive association between the amount of stock options and shares repurchases; a negative relation is instead estimated among stock-options and real investments. The above empirical evidence suggests the formulation of a second stylized fact:

SF2 A stronger stock-based remuneration of a firm's executives has a positive impact on the amount of share buybacks committed by the firm.

Altogether, SF1 and SF2 describe empirically documented properties concerning firm governance structure and firm investments. In the next sections we develop a formal theory replicating these stylized facts and shedding light on how the interaction among corporate governance characteristics may shape firm innovation and alter industry competition.

\section{Governance structure and firm investment choice: a static framework}

We begin by developing a simple static model to study how corporate governance structure shapes firm's investment choices. In the model firm choices are the result of a joint negotiation among three types stakeholders: managers, short- and long-term shareholders. We assume that each party is endowed with a specific bargaining power and pursues a specific objective. The bargaining power of the management is determined by the level of managerial independence from the whole body of shareholders. The relative importance of short- and long-term investors among shareholders is instead determined by their respective ownership share.

\subsection{The model}

Let's consider a firm existing only three periods $t=\{0,1,2\}$. At period $t=0$, a number of shortterm investors and a unique long-term investor jointly hold $n>0$ shares of the company. Let's denote by $\ell$ and $1-\ell$ (with $\ell \in(0,1)$ ) the proportion of the $n$ shares held, respectively, by the longterm and short-term investors. This defines the ownership structure of the firm. The two types of

\footnotetext{
${ }^{2}$ All these empirical evidences are consistent both with the sub-optimal rent extraction view (Walker, 2002), as well as with the optimal compensation view (Bolton et al., 2006).
} 
investors differ from each other in terms of their investment horizon. Short-term investors aim at selling their shares in period $t=1$. In contrast, the long-term investor holds his share until the firm is liquidated at $t=2$. A manager, in charge of the operational decisions of the firm completes the set of stakeholders and is rewarded with a fixed income, bonuses and shares of the firm. The fixed income $W^{F}$ is paid in period 1 and, for the sake of simplicity, set to zero. Bonuses are distributed in period $t=2$ as a fraction $\gamma$ of realized profits. In addition, $\beta$ restricted shares are assigned to the manager in period $t=0$ and can be monetised at period $t=1$. The firm is endowed with a budget that without loss of generality - is equal to 1 . In period $t=0$, the firm's budget can be allocated among two investment alternatives: a stock price-enhancing shares buyback $b$ and a productivity-enhancing R\&D investment $x=1-b$.

R\&D yields a profit at $t=2$, which is given by a concave function $\Pi(x)=\Pi(1-b)$ with:

$$
\Pi^{\prime}(1-b)>0, \Pi^{\prime \prime}(1-b)<0 \text { and } \Pi(0)=(1+r)^{2}, \quad r>0 .
$$

Notice that the function $\Pi(1-b)$ determines the monetary value that is distributed among shareholders when the firm is liquidated at $t=2$ (net from the payment of the manager bonus). The restriction on $\Pi(0)$ implies that for all $x \in(0,1]$ investing in $R \& D$ is more profitable than investing for two periods in a risk-free asset with interest rate $r>0$.

By allocating the amount $b$ to share buybacks, the firms commits to spend an amount $b$ to repurchase outstanding stocks from the investors in period $t=1$. In general, investors are willing to sell their shares in $t=1$ as long as they are compensated for the discounted terminal value of a stock, i.e. the proportional claim of a single share regarding the final liquidity of the firm. Hence, for a given buyback volume $b$, the value of holding a share in period $t=1$ must be equal to

$$
V_{1}=\frac{q(1-\gamma) \Pi(1-b)}{n+\beta-\frac{b}{V_{1}}},
$$

where $q \in(0,1)$ is the discount factor. We assume that short-term investors and the manager aim at selling their shares to the firm in $t=1$. The long-term investor, in contrast, is committed to keep the shares such that the maximum number of stocks to be repurchased by the firm is limited to $(1-\ell) n$ implying an upper cap $b^{\max }$ for the buyback volume. ${ }^{3}$ Solving (2) for $V_{1}$ leads to the equilibrium price at which the stocks are sold in $t=1$ that is

$$
V_{1}(b)=\frac{b+q(1-\gamma) \Pi(1-b)}{n+\beta} \text { with } 0<b<b^{\max }
$$

where $b^{\max }$ satisfies

$$
b^{\max }=(1-\ell) \frac{q(1-\gamma) \Pi\left(1-b^{\max }\right)}{\ell} .
$$

\subsection{Governance structure and firm choices}

We model the optimal allocation of firm resources $\left(x^{*}, b^{*}\right)$ as a trilateral Nash bargaining process ${ }^{4}$ between the manager and the two groups of shareholders (short-term and long-term ones). In the bargaining process the manager maximizes her income which at $t=0$ is equal to the discounted

\footnotetext{
${ }^{3}$ This implies also a minimal cap $x^{\min }=1-b^{\max } / V_{1}(b)$ of real investment.

${ }^{4}$ Note that Nash's axiomatic theory of bilateral bargaining extends unchanged to multilateral situations, see, e.g., Krishna and Serrano (1996).
} 
sum of bonus payments and to the realized amount from selling shares. The objective function of the manager is thus equal to:

$$
M(b)=\gamma q^{2} \Pi(1-b)+\beta q V_{1}(b)
$$

The two types of shareholders maximize their income at the investment horizon of interest. More precisely, the short-term shareholders maximize the share price in $t=1$, i.e. the price at which they are going to sell their stocks. Their objective function writes:

$$
S(b)=q V_{1}(b)
$$

The long-term investor, in contrast, maximizes the final value paid out at $t=2$ when the firm is liquidated. Hence his objective function is:

$$
L(b)=\frac{q^{2}(1-\gamma) \Pi(1-b)}{n \ell} .
$$

Finally, the joint objective function is the Nash product of the individual ones and writes:

$$
J(b)=M(b)^{\psi} S(b)^{\phi^{S}} L(b), \phi^{L}
$$

where $\psi>0, \phi^{S}>0$ and $\phi^{L}>0$ are parameters capturing the bargaining power of each stakeholder. Moreover, the condition $\psi+\phi^{S}+\phi^{L}=1$ holds. The parameter $\psi$ captures manager's autonomy. A high level of $\psi$ implies that the manager is powerful and makes the investment decision with few interference from the investors. Similarly, $\phi^{L}$ and $\phi^{S}$ capture the degree of influence that the longand the short-term shareholders exert. We further link shareholders' degree of influence to their proportion of firm shares (respectively $\ell$ and $1-\ell$ ), according to:

$$
\phi^{L}=(1-\psi) \ell \text { and } \phi^{S}=(1-\psi)(1-\ell)
$$

The set of parameters $\phi^{L}$ and $\phi^{S}$ and $\psi$ defines the whole governance structure of the firm, together with the ones related to the manager's remuneration $\gamma$ and $\beta .^{5}$ Firm investments result from the solution of the following maximization problem

$$
b^{*}=\arg \max _{b \in\left[0, b^{\max }\right]} M(b)^{\psi} S(b)^{\phi^{S}} L(b) .^{\phi^{L}}
$$

The solution of the above problem defines the optimal levels of share buybacks $b^{*}$ and of R\&D investment $\left(x^{*}=1-b^{*}\right)$.

\subsection{Comparative statics}

The problem stated in (10) does not have a closed form solution. However, we can use first-order conditions to characterize the marginal effects induced by changes in the parameters related to governance structure. This is the task accomplished by the next propositions. All proofs are presented in Appendix A. We first consider the marginal effect of a change in proportion of shares $\ell$ held by the long-term investor on firm investments.

\footnotetext{
${ }^{5}$ Note that in the following discussions, depending on the context, we will consider either parameters $\ell$ or $\phi^{L}$ and $\phi^{S}$ when referring to the power distribution between short- and long-term shareholders.
} 
Proposition 1. When $b^{*}$ is an interior solution of (10), the marginal effect of the proportion of shares $\ell$ held by long-term investors on the optimal level of buybacks $b^{*}$ is negative, i.e. $\frac{\partial b^{*}}{\partial \ell}<0$. In a corner solution with $b^{*}=b^{\text {max }}$, the sign of the marginal effect is negative as well.

The implications of Proposition (1) are clear. When the proportion of long-term shareholders increases the firm devotes more resources to $R \& D$ rather than to buybacks. This finding is fully consistent with Stylized Fact 1 (see Section 2), which states that a higher importance of short-term oriented investors is associated with a diverting of resources out of productive activities into financial activities. The next proposition considers the effect of a variation of the degree of manager's autonomy $\psi$.

Proposition 2. When $b^{*}$ is an interior solution of (10), the marginal effect of the manager's influence $\psi$ on the optimal level of buybacks $b^{*}$ is ambiguous. In particular, there exist threshold values $\tilde{\gamma} \in(0,1)$ and $\tilde{\beta} \geq 0$ such that:

1. if $\beta \geq \tilde{\beta}$, then $\frac{\partial b^{*}}{\partial \psi} \geq 0$,

2. if $\beta<\tilde{\beta}$, then $\frac{\partial b^{*}}{\partial \psi}>0$ for $\gamma<\tilde{\gamma}$ and $\frac{\partial b^{*}}{\partial \psi} \leq 0$ for $\gamma \geq \tilde{\gamma}$.

In a corner solution with $b^{*}=b^{\text {max }}$, the managerial influence $\psi$ has no effect on $b^{*}$.

The implications of Proposition 2 are less straightforward. The sign of the marginal effect depends on the composition of the manager's remuneration. Nevertheless, the results are quite intuitive as only those compensation schemes that put a stronger emphasis on bonuses rather than stocks generate stronger incentives to invest in $\mathrm{R} \& \mathrm{D}$. In fact, only if the bonus parameter $(\gamma)$ is relatively large and, at the same time, the number of shares $(\beta)$ issued to the manager is limited, then an increase in the decision power of the management board has a positive effect on the real investment level (a negative one on buybacks).

We now turn to analyze the marginal effects of a change in the parameters determining manager's remuneration. The following proposition summarizes the effects of a variation in the share-based remuneration parameter $\beta$.

Proposition 3. When $b^{*}$ is an interior solution of (10), the marginal effect of the share-based remuneration parameter $\beta$ on the optimal buyback level $b^{*}$ is always positive, i.e. $\frac{\partial b^{*}}{\partial \beta}>0$. In a corner solution with $b^{*}=b^{\text {max }}$, a change in $\beta$ has no effect on the optimal buyback level $b^{*}$.

This proposition shows that an increase in the share-based compensation of the manager creates stronger incentives to invest in buybacks and it crowds out R\&D investments. This is in line with Stylized Fact 2 (see Section 2). Finally, the marginal effect of the bonus-related parameter $\gamma$ can be characterized as follows:

Proposition 4. When $b^{*}$ is an interior solution of (10), the marginal effect of the bonus parameter $\gamma$ on $b^{*}$ is ambiguous. In particular, there exist threshold values $\hat{\gamma} \in(0,1)$ and $\hat{\beta} \geq 0$ such that:

1. if $\beta \geq \hat{\beta}$, then $\frac{\partial b^{*}}{\partial \gamma} \leq 0$,

2. if $\beta<\hat{\beta}$, then $\frac{\partial b^{*}}{\partial \gamma}<0$ for $\gamma<\hat{\gamma}$ and $\frac{\partial b^{*}}{\partial \beta} \geq 0$ for $\gamma \geq \hat{\gamma}$.

In a corner solution with $b^{*}=b^{\text {max }}$, an increase in $\gamma$ always reduces $b^{*}$. 
The last proposition indicates that an increase in bonus payments decreases share buybacks in favour of a high R\&D investment only if the manager has a high share-based remuneration $\beta$. This result is explained by the fact that a higher $\beta$ does not only affect the incentives of managers but also the ones of long-term and short-term investors, because it decreases their respective pay-offs (see Equations (2) and (3) above). This creates stronger incentives to increase the firm value via higher profits from R\&D investments.

\section{Governance structure, innovation and competition: a dynamic frame- work}

In the previous section we demonstrated that firm governance structure has a strong impact on firm investment choice by using a static and fully deterministic model. In this way, we could identify which governance structures are associated with high levels R\&D investments and which instead generate a high level of share buybacks. However, the static framework cannot be used to investigate how corporate governance impacts on industry competition and evolution. For this reason, we now embed our simple model of firm investment choice in a fully dynamic framework. Building on Dawid et al. (2019), this new framework comprises a dynamic industry model with heterogeneous firms, endogenous technical change and a stylized financial market. Our modelling approach is very much inspired by evolutionary models of industrial dynamics (see e.g. Dosi et al., 1995; Winter et al., 2003; Dosi et al., 2017) and populated by boundedly-rational agents that take decisions sequentially. R\&D investment increases firm competitiveness whereas share buybacks potentially drive up the share price on the financial market. Agents in this framework have bounded rationality. Although they take decisions on the grounds of constrained maximization they have limited information sets.

\subsection{Competition and innovation in the goods market}

We assume a market populated by $n$ firms (indexed by $1, \ldots, n$ ) interacting in a monopolistic competitive environment. Each firm produces a firm-specific variety of the same good and the demand of a firm $i$ is given by

$$
Q_{i, t}^{D}\left(P_{i, t}\right)=\frac{m_{t}\left(n P_{i, t}\right)^{1 /(\rho-1)}}{\sum_{j=1}^{n} P_{j, t}\left(n P_{j, t}\right)^{1 /(\rho-1)}} .
$$

where, $m_{t}$ measures the market size, $P_{i, t}$ the firm-level price and $\rho$ the inverse elasticity of substitution between the goods produced by the different firms in the industry.

Each firm sets the price according to mark-up pricing on unitary costs. The price of firm $i$ in period $t$ is determined by

$$
P_{i, t}=(1+\mu) \frac{w_{t}}{A_{i, t}},
$$

where $A_{i, t}$ describes the productivity level of the firm and $w_{t}$ is an industry specific wage level. The latter is proportional to average industry productivity $\bar{A}_{t}$ :

$$
w_{t}=\varphi \cdot \bar{A}_{t}, \quad \varphi>0
$$

The firm-specific operating profit $\Pi_{i, t}^{O}$ is computed as follows:

$$
\Pi_{i, t}^{O}=\left(P_{i, t}-\frac{w_{t}}{A_{i, t}}\right) \cdot Q_{i, t}^{D}-W^{F}=\Pi_{i, t}^{*}-W^{F}
$$


where $W^{F}$ represents a fixed management cost (i.e. a cost to pay the fix part salary of the boards of managers) and $\Pi_{i, t}^{*}$ defines the market profits.

The above formulation implies that all product-market activities of a firm, such as production and pricing, are promptly determined by the firm productivity level $A_{i, t}$ with respect to the average productivity $\bar{A}_{t}$ and by the characteristics of the demand.

The firm productivity level $A_{i, t}$ evolves endogenously over time due to process innovations carried out by the firm. Innovation is modelled as a stochastic process, which depends on firm's R\&D investments $I_{i, t}$ :

$$
A_{i, t}= \begin{cases}\zeta_{i, t} A_{i, t-1} & \text { with prob. } \alpha\left(1-\exp \left\{-\lambda \cdot\left(I_{i, t}\right)^{\tau}\right\}\right) \\ A_{i, t-1} & \text { else, }\end{cases}
$$

where the exponent $\tau \in(0,1]$ influences the marginal likelihood of success of R\&D intensity and $\lambda$ is a scaling factor. The productivity gain $\zeta_{i, t}$ is deterministic and it depends on the size of the gap between the firm's knowledge stock (proxied by the firm current productivity level) and the industry-specific technological frontier $A^{\max }$ :

$$
\zeta_{i, t}=\zeta \cdot \max \left\{1,\left(\frac{A_{t-1}^{\max }}{A_{i, t-1}}\right)\right\} .
$$

Thus, the more distant a firm is to the frontier, the easier it might be for such a firm to marginally extend its knowledge stock. This is due to the fact that knowledge, with a growing distance from the frontier, becomes less tacit and implicit and therefore easier to acquire.

\subsection{Financial markets and share prices determination}

All firms in the industry are assumed to be listed companies with $N_{i, t}$ outstanding shares traded in every period $t$ at a price $V_{i, t}$, determined in a decentralized financial market. The number of firm outstanding shares evolves in every period, not only due to buybacks $B_{i, t}$ but also because the manager receives $\beta$ new shares (without dividends) in every period as part of her compensation (see section 4.3). Hence, the law of motion for the total number of outstanding shares is: ${ }^{6}$

$$
N_{i, t}=N_{i, t-1}+\beta-\frac{B_{i, t-1}}{V_{i, t-1}} .
$$

As in Section 3, we assume that outstanding shares are held by short-term and long-term investors. Long-term investors own a fixed fraction $\ell$ of outstanding shares. They only trade to keep their proportion of shares at the constant level $\ell$, such that the total number of shares owned by long-term investors is

$$
N_{i, t}^{L}=\ell N_{i, t}
$$

The remaining $1-\ell$ fraction of outstanding shares is owned by $S$ short-term risk-averse investors who aim at capital gains by trading firm shares in the financial market. Short-term traders are of different types, because they have heterogeneous expectations about the evolution of future firm share prices.

More precisely, following Brock and Hommes (1998) and Dawid et al. (2019), we assume that at any period $t$ every short-term trader of type $h$ allocates her wealth $W_{h, t}$ between the shares of listed

\footnotetext{
${ }^{6}$ Notice that in equation (17) we are assuming that shares which are bought back by the firm are then retired from the market.
} 
firms and a perfectly-elastically supplied safe asset that yields a return $r$. The law of motion for the evolution of trader's $h$ wealth reads:

$$
\mathbb{E}_{h, t}\left[W_{h, t+1}\right]=\hat{W}_{h, t+1}=(1+r) W_{h, t}+z_{h, i, t}\left[\hat{V}_{h, i, t+1}+\hat{d}_{i, t+1}-(1+r) V_{i, t}\right] .
$$

where $\mathbb{E}_{h, t}\left[W_{h, t+1}\right]$ is expected one-period-ahead trader's wealth, $z_{h, i, t}$, is the share of trader's wealth allocated to firm i's stocks in period $t, \hat{V}_{h, i, t+1}$ and $\hat{d}_{h, i, t+1}$ are, respectively, the expected stock price and dividend of firm $i$, whereas $V_{i, t}$ is the current stock price. Notice that the term in square brackets measures the excess return to trader $h$ from investing in firm $i$ (with respect to the investment in the safe asset).

Furthermore, we assume that each trader of type $h$ is a myopic mean-variance maximizer. Her demand for the stocks of firm $i$ at time $t, z_{h, i, t}$ thus solves:

$$
\max _{z_{h, i, t}}\left\{E_{h, t}\left[W_{h, t+1}\right]-(\tilde{a} / 2) \operatorname{Var}_{h, t}\left(W_{h, t+1}\right)\right\}
$$

where $\operatorname{Var}_{h, t}\left(W_{h, t+1}\right)$ is the variance of the one-period-ahead wealth and $\tilde{a}$ is the risk aversion coefficient. The solution to the above maximization problem yields the following demand function: (see Brock and Hommes, 1998):

$$
z_{h, i, t}=\frac{\hat{V}_{h, i, t+1}+\hat{d}_{i, t+1}-(1+r) V_{i, t}}{\tilde{a} \hat{\sigma}^{2}}
$$

wherein $\hat{\sigma}^{2}$ is traders' $h$ expectation of the conditional variance of excess returns per share. ${ }^{7}$ Notice that the demand function for the stock of firm $i$ by a trader $h$ is an increasing function of the expected price and of the expected dividend of the firm. We assume short-term traders have homogeneous adaptive expectations about future dividends of a firm $i$

$$
\mathbb{E}_{h, t}\left[d_{i, t+1}\right]=\hat{d}_{i, t+1}=(1-\phi) \mathbb{E}_{h, t-1}\left[d_{i, t}\right]+\phi d_{i, t},
$$

where $(1-\phi)$ determines the expectations persistence. In contrast to dividends expectations, shortterm traders differ in their beliefs about future stock prices of a firm. In particular, following Dawid et al. (2019) we assume that they evaluate differently the impact of share buybacks $B_{i, t}$ on the future firm share price. In this respect, short-term traders are divided in two categories: optimists ( indexed by" $\mathrm{o}^{\prime \prime}$ ) who expect a positive impact of share buybacks on share price, and pessimists (indexed by " $\mathrm{p}$ "), who instead expect a negative impact. The one-period-ahead expected share price by a shortterm trader of type $h$ (with $h \in\{o, p\}$ ) can then be written as:

$$
\mathbb{E}_{h, t}\left[V_{i, t+1}\right]=\hat{V}_{h, i, t+1}=V_{i, t-1}\left(1+\kappa_{h} \frac{B_{i, t}}{V_{i, t} N_{i, t}}\right) .
$$

The coefficient $k_{h} \in\left\{k_{o}, k_{p}\right\}$ with $\kappa_{p}<0<\kappa_{o}$ captures the sensitivity of trader's beliefs to share buybacks $B_{i, t}$.

Finally, assuming that the proportion of optimists and pessimists are, respectively, $\theta$ and $1-\theta$ and that the financial market clears at every period, we obtain ${ }^{8}$ that the market-clearing share price

\footnotetext{
${ }^{7}$ More precisely, the expression for the conditional variance of excess returns is $\left.\hat{\sigma}^{2}=\operatorname{Var}_{h, t}\left(\hat{V}_{h, i, t+1}+\hat{d}_{i, t+1}-(1+r) V_{i, t}\right)\right)$

${ }^{8}$ More technical details about the determination of the equilibrium share price be found in Appendix $B$.
} 
$V_{i, t}^{*}$ is determined by the positive root of the following quadratic equation (see Dawid et al., 2019):

$$
V_{i, t}^{*}=\frac{X_{1, i, t}+\sqrt{X_{1, t, i}^{2}+4(1+r) X_{2, i, t} B_{i, t}}}{2(1+r)}
$$

where (after setting $a=\tilde{a} / S)$,

$$
\begin{aligned}
& X_{1, i, t}=\hat{d}_{i, t+1}+V_{i, t-1}-a \hat{\sigma}^{2}(1-\ell) N_{i, t} \\
& X_{2, i, t}=\frac{\left[\theta \kappa_{o}+(1-\theta) \kappa_{p}\right] V_{i, t-1}}{N_{i, t}}+a(1+\ell) \hat{\sigma}^{2} .
\end{aligned}
$$

\subsection{The firm decision problem and stakeholders bargaining}

A firm $i$ in each period must decide about the level of R\&D investment and of share buybacks. Firm R\&D affects firm productivity level $A_{i, t}$ and its price competitiveness in the goods market (see Section 4.1). Share buybacks impact on the share price $V_{i, t}$ (see previous section). Similarly to the static framework developed in Section 3.2, the optimal levels of R\&D investments $I_{i, t}^{*}$ and of buybacks $B_{i, t}^{*}$ are set by the solution to a constrained trilateral Nash-bargaining problem among the three stakeholders of the firms - i.e. the manager, the short-term and the long-term investors. More formally the foregoing problem can be written as:

$$
\begin{gathered}
\max _{I_{i, t}, B_{i, t}} \mathcal{M}_{i, t}^{\psi} \mathcal{S}_{i, t}^{\phi^{S}} \mathcal{L}_{i, t}^{\phi^{L}} \\
\text { subject to } \\
I_{i, t}+B_{i, t} \leq S_{i, t}(1-\delta)-W^{F} .
\end{gathered}
$$

$\mathcal{M}, \mathcal{S}, \mathcal{L}$ define the in-period income of each stakeholder and the budget constraint indicates that the resources for R\&D investments and buybacks are limited by the presence of internal resources net of the fixed management costs.

The manager objective function in period $t$ is:

$$
\mathcal{M}_{i, t}=W^{F}+\gamma \Pi_{i, t}^{*}+\beta V_{i, t} .
$$

The first term refers to a fix salary which the manager obtains independently from the firm performance. The second one describes the bonus salary, directly linked to the firm profits. The third term captures the gains from selling the $\beta$ newly issued shares that the manager obtains as remuneration and that she immediately cashes-in. The manager thus faces a trade-off between increasing her bonus by increasing profits $\Pi_{i, t}^{*}$ and reaping instead a capital gain on the firm share price $V_{i, t}$, which can be influenced by shares buybacks (see previous section). The parameters $\gamma$ and $\beta$ in the above objective function determine the manager incentives toward either real investments or buybacks.

Furthermore, the objective function of the short-term investor in period $t$ writes:

$$
\mathcal{S}_{i, t}=N_{i, t-1}^{S}\left[\left(V_{i, t}-V_{i, t-1}\right)+d_{t}\right]
$$

and is driven by the capital gain on the $N_{i, t}^{S}$ shares achieved via an increase in the share price. ${ }^{9}$

\footnotetext{
${ }^{9}$ Notice that short-term investor's incentives at time $t$ are affected only by the current share price $V_{i, t}$. This is because both the previous period share price $V_{i, t-1}$ and the dividends $d_{t}$ have been determined by the previous decisions
} 
Finally, the long-term investors' objective function reads

$$
\mathcal{L}_{i, t}=N_{i, t}^{L} \hat{d}_{i, t+1}^{L}+\left(V_{i, t}-V_{i, t-1}\right) N_{i, t-1}^{L} .
$$

Differently from the short-term speculators, long-term investors takes into account the expected dividends $\hat{d}_{i, t+1}^{L}$ in the next period. The expected dividend per share, conditioned on the choice of $I_{i, t}$ and $B_{i, t}$, is then

$$
\hat{d}_{i, t+1}^{L}=\frac{(1-\gamma)(1+r) \delta \cdot \mathbb{E}_{t}\left[\Pi_{i, t}^{*} \mid I_{i, t}\right]}{N_{i, t}+\beta-\frac{B_{i, t}}{V_{t}}} .
$$

Notice that long-term investors extrapolate the future dividend stream naively by taking only the one-period-ahead expectation into account. ${ }^{10}$

To solve the problem in (25), we equalize the weighted marginal returns from an increase in $I$ and in $B$. Accordingly, the optimal solution for each single firm is defined as the pair of values $\left(I_{i, t}^{*}, B_{i, t}^{*}\right)$ that solves

$$
\frac{d J_{i, t}}{d I_{i, t}}=\frac{d J_{i, t}}{d B_{i, t}}
$$

The derivatives of the Nash product with respect to $I_{i, t}$ and $B_{i, t}$ are thereby expressed by

$$
\begin{aligned}
\frac{d J_{i, t}}{d I_{i, t}} & =\left(\psi \mathcal{M}_{i, t}^{-1} \frac{d \mathcal{M}_{i, t}}{d I_{i, t}}+\phi^{L} \mathcal{L}_{i, t}^{-1} \frac{d \mathcal{L}_{i, t}}{d I_{i, t}}\right) \mathcal{M}_{i, t}^{\psi} S_{i, t}^{\phi^{S}} \mathcal{L}_{i, t}^{\phi^{L}} \\
\frac{d J_{i, t}}{d B_{i, t}} & =\left(\psi \mathcal{M}_{i, t}^{-1} \frac{d \mathcal{M}_{i, t}}{d B_{i, t}}+\phi^{S} \mathcal{S}_{i, t}^{-1} \frac{d \mathcal{S}_{i, t}}{d B_{i, t}}+\phi^{L} \mathcal{L}_{i, t}^{-1} \frac{d \mathcal{L}_{i, t}}{d B_{i, t}}\right) \mathcal{M}_{i, t}^{\psi} \mathcal{S}_{i, t}^{\phi^{S}} \mathcal{L}_{i, t}^{\phi^{L}}
\end{aligned}
$$

It should be noted that the partial derivative $\frac{\partial \mathcal{S}_{i, t}}{\partial I_{i, t}}=0$. This implies that R\&D investments do not affect the objective of short-term investors. ${ }^{11}$ The optimal resource allocation $\left\{I_{i, t}^{*}, B_{i, t}^{*}\right\}$ can be determined numerically.

\subsubsection{Timeline of events}

At every time step $t$, the following sequence of events takes place.

1. Firms decisions. The firm determines the dividends $D_{i, t}$ which are a fraction $\delta$ of the savings $S_{i, t}$ available at the beginning of period $t$. Then, the firm also determines the optimal level $I_{i, t}^{*}$ and $B_{i, t}^{*}$ given the budget constraint:

$$
I_{i, t}^{*}+B_{i, t}^{*} \leq S_{i, t}(1-\delta)-W^{F}
$$

If, however, $S_{i, t}(1-\delta)<W^{F}$, then the firm cannot meet its financial obligations and declares bankruptcy. In this case, the firm exits the market.

2. Financial market activities. The firm spends $B_{i, t}^{*}$ to repurchase shares and the share price $V_{i, t}$ is determined according to equation (24). The manager sells the $\beta$ restricted shares received as stock-based remuneration in the previous period.

$I_{i, t-1}^{*}, B_{i, t-1}^{*}$ (see section 4.3.1) and are consequently given at the time of the decision making in $t$.

${ }^{10}$ The expectations formed by the long-term investors differ from the one of the short-term traders in financial markets (see Equation 22 in the next section). The rationale for this difference is that long-term investors have more knowledge about the firm and can therefore form more sophisticated dividend expectations taking into account the effect of R\&D investments and buybacks in period $t$ on the dividends in $t+1$.

${ }^{11}$ Additional equations related to the derivation of the optimal choice are detailed in Appendix C. 
3. Innovation activities. The firm spends $I_{i, t}^{*}$ to perform R\&D and the productivity for the upcoming production cycle $A_{i, t}$ is determined.

4. Goods market activities. The firm realizes the market profit $\Pi_{i, t}^{*}$

5. Accounting activities. The bonus for the manager $\gamma \Pi_{i, t}^{*}$ is realized; the manager also receives $\beta$ restricted shares (without dividends) together with a base fixed income $W^{F}$. After these operations, the payment account of the next period is determined by

$$
S_{i, t+1}=(1+r)\left[S_{i, t}+(1-\gamma) \Pi_{i, t}^{*}-D_{i, t}-I_{i, t}^{*}-B_{i, t}^{*}-W^{F}\right] .
$$

\section{Calibration and empirical validation}

The high-dimensionality of the dynamical model presented in the previous section prevents an analytical investigation of its properties. Thus, in the following sections, we carry out simulation experiments with a calibrated instance of the model. ${ }^{12}$ We use a calibration strategy aiming at minimizing the squared sum of relative deviations between simulated data and empirical data, after the model has reached a stationary state with respect to market structure. In order to do so, we define a set of industry variables $\hat{\mathbf{y}}$ as targets and a set of key structural parameters $\theta^{*}$ to be calibrated. Then, we sample the parameter space by selecting a discrete set $\Theta$ of values and run $M$ Monte Carlo simulations across this parameter sub space. ${ }^{13}$ Next, we compute the simulated first moments $\overline{\mathbf{y}}(\theta)$ for each parameter constellation in $\Theta$ where the moments are computed as averages of the simulated variables $\mathbf{y}_{t}(\theta)$ in steady state. Finally we compute the optimal parameter vector $\theta^{*} \in \mathbf{\Theta}$ such that

$$
\theta^{*}=\underset{\theta \in \Theta}{\arg \inf }\left((\overline{\mathbf{y}}(\theta)-\hat{\mathbf{y}}) \frac{1}{\hat{\mathbf{y}}}\right)^{T}\left((\overline{\mathbf{y}}(\theta)-\hat{\mathbf{y}}) \frac{1}{\hat{\mathbf{y}}}\right)
$$

where

$$
\overline{\mathbf{y}}(\theta)=\frac{1}{M} \frac{1}{T_{L}} \sum_{m=1}^{M} \sum_{t=T-T_{L}+1}^{T} \mathbf{y}_{m, t}(\theta) .
$$

The key target variables that we aim to replicate with this model are: the average productivity growth rate in the whole industry; the industry-wide buybacks-to-R\&D investment ratio; and the industry-wide buybacks-to-dividends ratio. For all of these variables, we focus on European data. The results of the calibration procedure are presented in Table 1 while the benchmark parameter vector $\theta^{*}$ is included in Appendix D. The calibration leads to an outcome which closely resembles the empirical data: the aggregate ratios between buybacks and R\&D and between buybacks and dividends are pretty close to the ones evidenced by Sakinc (2017) analysing the investment behaviour of firms listed in the S\&P 350 Europe. ${ }^{14}$ For productivity growth, we use EU-KLEMS data that measures productivity at the total industry level. Here, we focus on German, French and UK data since the firms in this index from these countries constitute around $63 \%$ of the total S\&P 350 Europe market capitalization. The target value of $0.59 \%$ p.a. is obtained by averaging the productivity growth

\footnotetext{
${ }^{12}$ The model has been implemented in C using the FLAME simulation environment. The code is available at https: //github.com/ETACE/Governance.

${ }^{13}$ Since the model complexity is relatively low we here do not need the adoption of an efficient sampling algorithm.

${ }^{14}$ It shall be noted that there is a substantial difference for these two ratios between European and US data, as the buyback activity is much more pronounced in the US. For example, according to Lazonick (2014) the buybacks-to-dividends ratio is around 1.46 in the US.
} 
rates of the total industry in each country over the period 1998-2015. ${ }^{15}$ Also for this variable, the calibration generates reasonable outcomes.

\begin{tabular}{|c|c|c|c|}
\hline Variable & Simulated value & Empirical Target & Source \\
\hline Productivity growth (\%) & $\begin{array}{l}0.54 \% \\
(0.015)\end{array}$ & $0.59 \%$ & $\begin{array}{l}\text { EU-KLEMS } \\
\text { (Jäger, 2017) }\end{array}$ \\
\hline $\begin{array}{l}\text { Industry-wide } \\
\text { buybacks-R\&D ratio }\end{array}$ & $\begin{array}{c}0.49 \\
(0.081)\end{array}$ & 0.44 & $\begin{array}{l}\text { S\&P } 350 \text { Europe } \\
\text { (Sakinc, 2017) }\end{array}$ \\
\hline $\begin{array}{l}\text { Industry-wide } \\
\text { buybacks-dividends ratio }\end{array}$ & $\begin{array}{c}0.15 \\
(0.020)\end{array}$ & 0.22 & $\begin{array}{l}\text { S\&P } 350 \text { Europe } \\
\text { (Sakinc, 2017) }\end{array}$ \\
\hline
\end{tabular}

Table 1: Empirical targets and simulated values for selected variables. Standard deviations in parentheses.

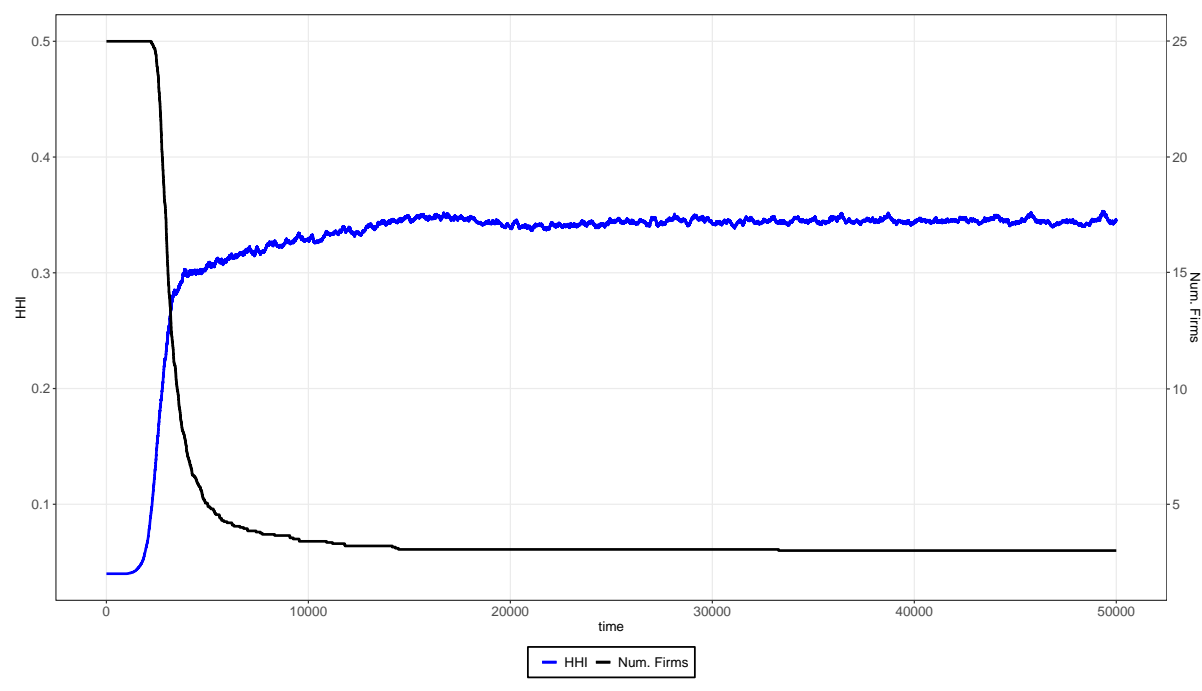

Figure 1: Time series of the Herfindahl-Hirschman index and the number of firms in the industry for the benchmark parametrization; average across 20 MonteCarlo simulations. Presence of unit root for the time series of the Herfindahl index is rejected at the $1 \%$ level by the augmented Dickey-Fuller test for the periods $t \in[20001,50000]$.

Furthermore, we observe that without targeting our calibration exercise to any value of market concentration, the model simulated under the baseline parametrization converges to a steady state where the Herfindahl index measures about 0.33 . This means that, even by starting with 25 equally sized firms in a monopolistic competitive market environment, innovation and technical change generate substantial market concentration where on average only 3 firms satisfy the vast majority of the demand. This result is observable in Figure 1 and is also in line with the industrial life cycle literature (e.g. Klepper, 1996; Jovanovic and MacDonald, 1994) suggesting that over the life cycle of an industry there is a shake-out process by which the number of firms steadily declines until converging to a stable market structure with some degree of concentration. ${ }^{16}$

\footnotetext{
${ }^{15}$ We also exclude from the computation the $2008-2010$ period as the crisis led to extreme growth rates imputable to events occurring outside the industry domain.

${ }^{16}$ In our model, all the entry happens at time 1 and we abstract from subsequent entry. In addition, our result differs from the theoretical limit discussed by Dosi and Kaniovski (1994) who suggest that in a dynamic environment with increasing returns the monopoly should be the emergent market structure. Our result is driven by the assumption in equation 16 according to which firms that are more distant from the technological frontier obtain larger productivity gains from innovation compared to firms close to it. In fact, this diminishes the strength of the increasing returns entailed by equations 11 and 15 .
} 


\section{Results}

After having calibrated the model and verified its ability to match empirical evidence, we proceed to a battery of Monte Carlo simulation exercises to explore how firm governance structure impacts on industry evolution with a special emphasis on the relation between innovation and competition. We study the impact of governance structure on industry properties when the industry has reached the steady state as well as during the convergence process.

\subsection{Steady-state implications of governance structure}

We begin by studying how an exogenous variation in the governance structure of all firms impacts on market concentration and productivity growth when the industry has reached a steady state. We explore how these two market aggregates are affected by all possible combinations of management autonomy on the one side, and by the distribution of ownership shares across short- and long-term investors on the other side. In the model these forces are respectively measured by the parameters $\psi, \phi^{L}$ and $\phi^{S}$ with $\psi+\phi^{L}+\phi^{S}=1$ (see Section 4.3).

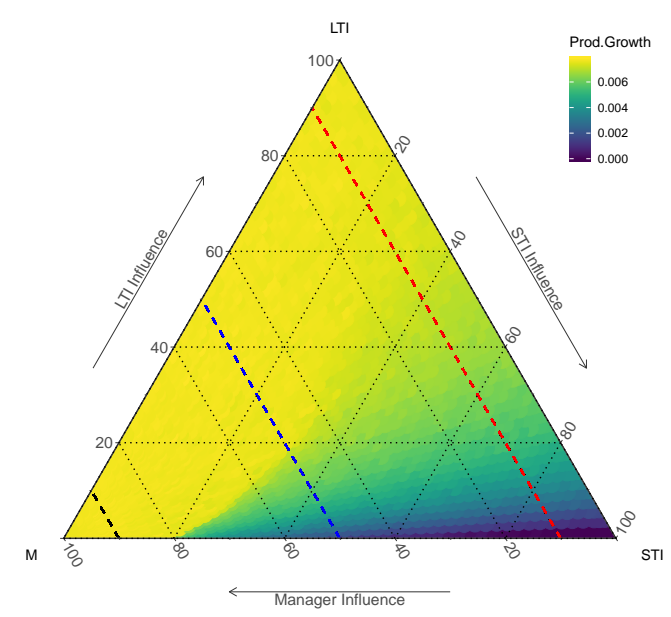

(a)

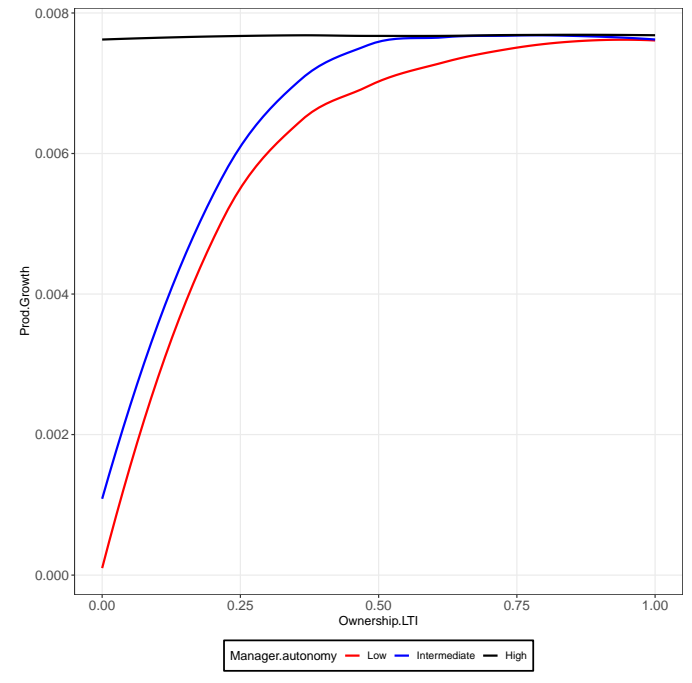

(b)

Figure 2: Average annual productivity growth of firms at $t=50000$. (a) Triangular heat-map over the governance structure space. The three coloured dashed lines represent fixed levels of the manager autonomy (red: $\psi=10 \%$; blue: $\psi=50 \%$; black: $\psi=90 \%$ ). (b) Spline-smoothed productivity growth as a function of the proportion of shares $\ell$ controlled by the long-term investors, evaluated for the different levels of the manager autonomy (colours and levels are equal to the dashed lines of panel a).

Figure 2 (a) displays the outcomes in terms of productivity growth at time period $t=50000$ across all the possible parameter combinations which form a triangular simplex. Starting from the corners, we record the highest growth rates in cases where most of the bargaining power is assigned to the manager and/or to the long-term investors (from the bottom-left, to the top corner). The lowest growth rates can instead be observed under a governance structure oriented toward shortterm investors (STI, bottom-right corner). Moving to the central part of the triangle, it appears that, given a specific level of manager autonomy, there is a monotonically increasing relation between the bargaining power of long-term investors (LTI) and the productivity growth rate. The latter result is also highlighted by panel (b) in the figure that plots, for given levels of the manager autonomy $\psi$, the 
relation between average productivity growth and the proportion $\ell$ of shares controlled by the LTI. In particular, we fix $\psi=\{0.1,0.5,0.9\}$ corresponding to a low, medium and high level of manager independence (these three levels are also displayed in panel (a) as dashed lines).

Furthermore, increasing the proportion of shares controlled by long-term investors leads to faster technical progress when manager's autonomy is low (respectively the red and blue splines in the plot in panel b). In contrast, changes in the composition of shareholders do not have effects on productivity growth when the manager is already very powerful (cf. the black line in the same plot). This neutrality effect however reflects the payment scheme of the manager in the baseline parametrization, which increases incentives towards R\&D investments vs. buybacks (i.e. in the baseline calibration $\gamma$ is relatively high with respect to $\beta$, see equation 26). In section 6.2.1 we carry out additional experiments on the effects of manager's payment scheme and we show that the above neutrality does not always hold true.

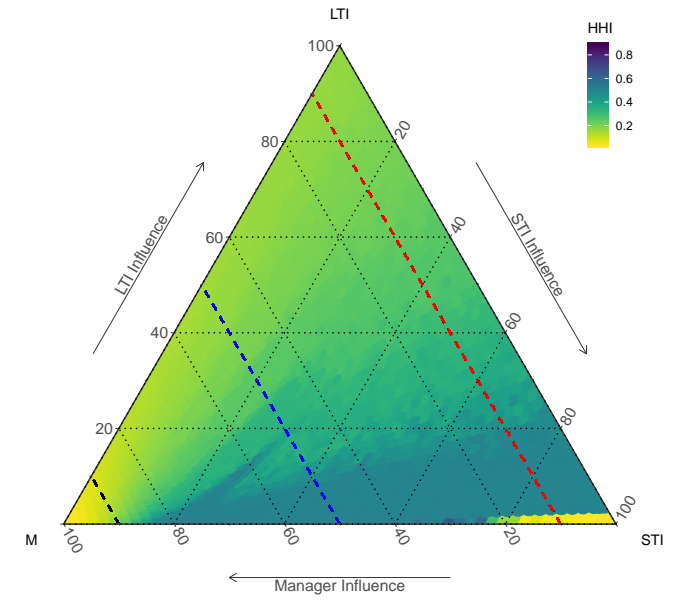

(a)

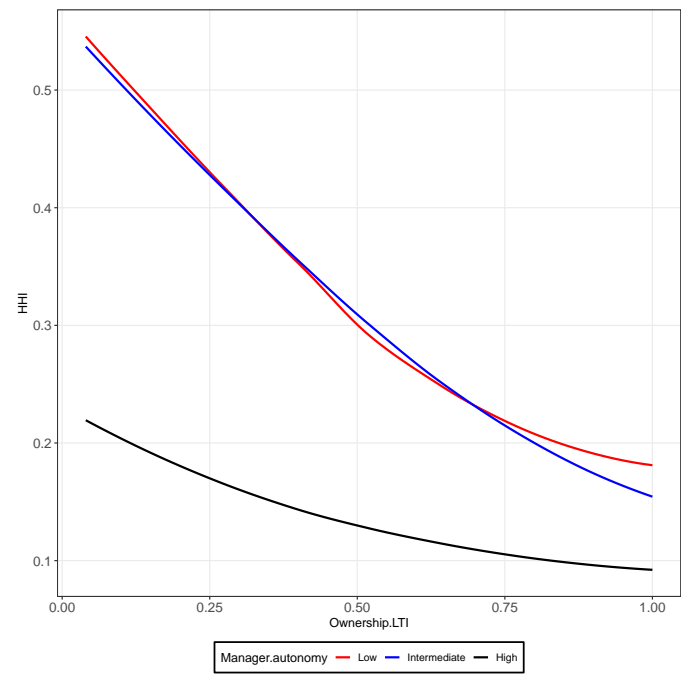

(b)

Figure 3: Herfindahl-Hirschman Index at $t=50000$. (a) Triangular heat-map over the governance structure space. The three coloured dashed lines represent fixed levels of the manager autonomy (red: $\psi=10 \%$; blue: $\psi=50 \%$; black: $\psi=90 \%$ ). (b) Spline-smoothed Herfindahl-Hirschman Index as a function of the proportion of shares $\ell$ controlled by the long-term investors, evaluated for the different levels of the manager autonomy (colours and levels are equal to the dashed lines of panel a)

Finally, Figure 3 studies the effects of changes in corporate governance structure on steady-state industry concentration, with the latter measured by the Herfindahl index. The plot in panel (b) - a subset of the results displayed in panel (a), along the three dashed lines - suggests two main conclusions. First, an increase in the long-term ownership of the firm has a positive impact on competition. This holds true, irrespectively of the degree of management autonomy. Second, when the management has an almost exclusive control of the firm (i.e. the black line with $\psi=0.9$ ), the Herfindahl index never reaches values larger than $22 \%$ (this value is obtained when all the shares are controlled by short-term investors). ${ }^{17}$

\footnotetext{
${ }^{17}$ It is also worth noticing a very peculiar case in the bottom-right corner of panel (a) in which no (or only few) real investments are carried out. In this case all firms remain constant at their original productivity levels and the industry structure does not evolve. Thus the steady state market concentration is the lowest.
} 


\subsection{Industry transition and governance structure}

We now investigate how changes in corporate governance structure affect industry dynamics during the convergence towards the steady-state. We present simulation results at iterations 2500, 10000, 50000, which represent three different phases (young, mature and steady state) of the industry life-cycle.

The relation between governance structure and productivity growth observed in steady state (see Figure 4) holds also during the convergence process. For any level of management's independence, an industry where long-term investors have a large ownership share displays higher productivity growth rates than an industry dominated by short-term investors. However, the relation is quantitatively different at different stages of the industry evolution. For a young industry $(t=2500)$ a small fraction of short-term investors is already sufficient to generate a significant drop in productivity growth. In contrast, in a mature industry $(t=10000)$, short-term investors slowdown productivity growth only if they exercise enough control over the firm. This quantitative differences suggests that focusing uniquely on the steady state provides only a partial account of the impact that governance structure exert on industry productivity performance.

The effects of the governance structure on productivity growth can be explained on the grounds of the incentive structure of the engaged stakeholders. We know from Proposition 1 that, ceteris paribus, a higher fraction of shares controlled by long-term investors leads to more real investments in R\&D. This can also be seen from the first order conditions of the maximization problem in Section 4.3 indicating that short-term investors are only interested in immediate capital gains and are therefore exclusively committed to buybacks. Long-term investors, in contrast, have a stronger preference for real R\&D investments that might affect future dividends. This type of investment, in turn, has a positive impact on productivity growth.

The relation between governance structure and market concentration shows both qualitative and quantitative differences during the different life-cycle phases (see Figure 5) . In quantitative terms, we observe an increasing level of concentration over time for intermediate configurations of governance structure. In a similar manner, after the convergence to a stable market structure $(t=50000)$ we observe higher values of concentration in the area where short-term investors exert a stronger influence on the firms. Qualitatively, instead, given a specific independence of the manager, we can observe a time variation in the relation between long-term investors' ownership and industry concentration: an inverted-U shape relation appears in the early phases of the industry life cycle and becomes steeper as the industry becomes more mature. Eventually, the hump-shaped relation collapses into a monotonically decreasing one in steady state. ${ }^{18}$

How do different ownership structures map into market concentration levels? Above we showed that the relation between long-term investors' share and market concentration becomes eventually decreasing as the industry approaches the steady state. ${ }^{19}$ This is explained by firm incentives towards R\&D depending on firm relative distance from the technological frontier. These incentives are well captured by the productivity gain each firm expects to obtain from R\&D investment. In this respect, Figure 6 shows the time-evolution (for the same representative MonteCarlo run) of the difference in expected productivity growth between the technological leader and the average of the

\footnotetext{
${ }^{18}$ Except for the special cases in which the short-term investors have almost full control over the firms $\left(\phi^{S}>0.98\right)$ and management autonomy is relatively low (see also footnote 17).

${ }^{19}$ In young industries the relation is instead hump-shaped. This is explained by the fact that low R\&D intensities of firms controlled by short-term oriented investors lead to a slow pace in the differentiation process of firms in the industry. When firms are hardly investing in $\mathrm{R} \& \mathrm{D}$, their competitiveness, and in turn market shares, remain relatively close together and it takes quite a long time until a more concentrated market structure emerges
} 


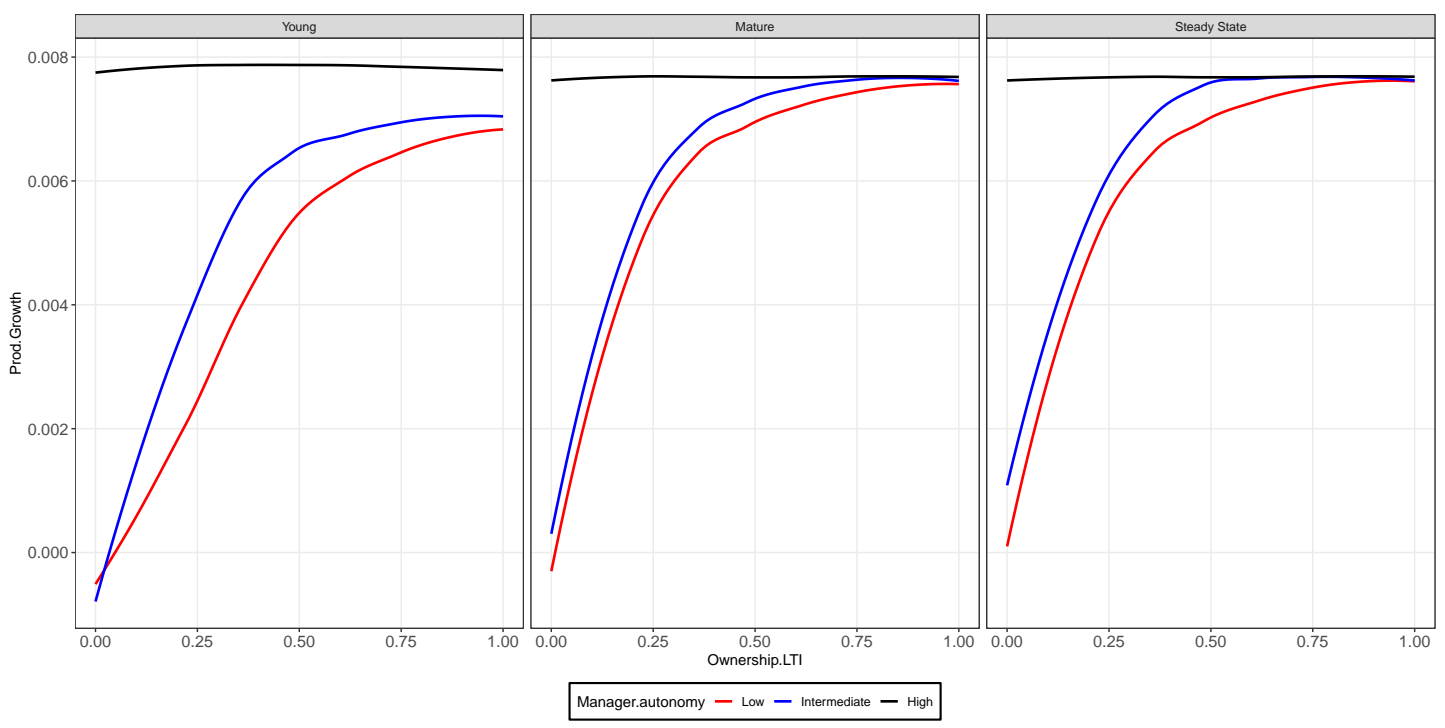

Figure 4: Impact of governance structure on productivity growth over time at different industry stages.

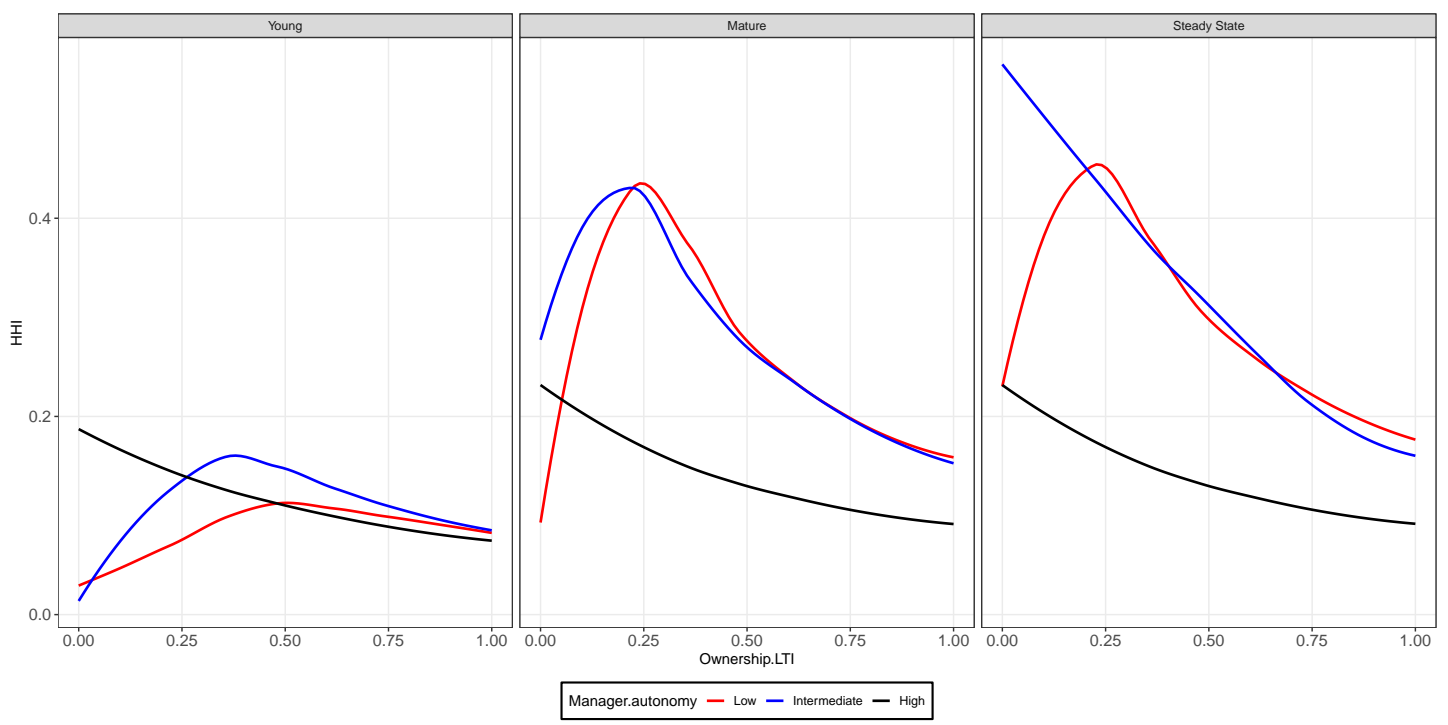

Figure 5: Impact of governance structure on market concentration (HHI:Herfindahl-Hirschman index) at different industry stages.

four closest followers. ${ }^{20}$ The left plot refers to a situation where short-term investors have control of firms, whereas the right plot correspond to the situation where long-term investors are dominant. Note that, in the two graphs, positive values of the difference imply productivity divergence across firms whereas a negative values results in convergence.

It is clear from the plots in Figure 6 that, in industries with more short-term oriented governance structures, the expected gain of the technological leader increases over time. This generates a dynamic often labelled as "pre-emption" in the industrial organization literature (see e.g. Fudenberg et al., 1983), i.e. one characterized by stronger divergence and market concentration over time. In contrast, in industries where long-term investors dominate, industry followers eventually get higher expected gains than the leader (the difference with leader becomes negative after $t=2500$ ). This

\footnotetext{
${ }^{20}$ These are numerically computed as the expected value of productivity increase, conditional on the current R\&D intensity. Formally, this reads $\mathbb{E}\left[\frac{\Delta A_{i, t}}{A_{i, t-1}}\right]=\alpha\left(1-\exp \left\{-\lambda \cdot R_{i, t}^{\tau}\right\}\right)\left(\zeta_{i, t}-1\right)$ where the first part represents the probability of success as a function of R\&D intensity and the second part the productivity jump size.
} 
triggers more R\&D spending and the technological catch-up of the neck-and-neck followers and, ultimately, lower market concentration levels.

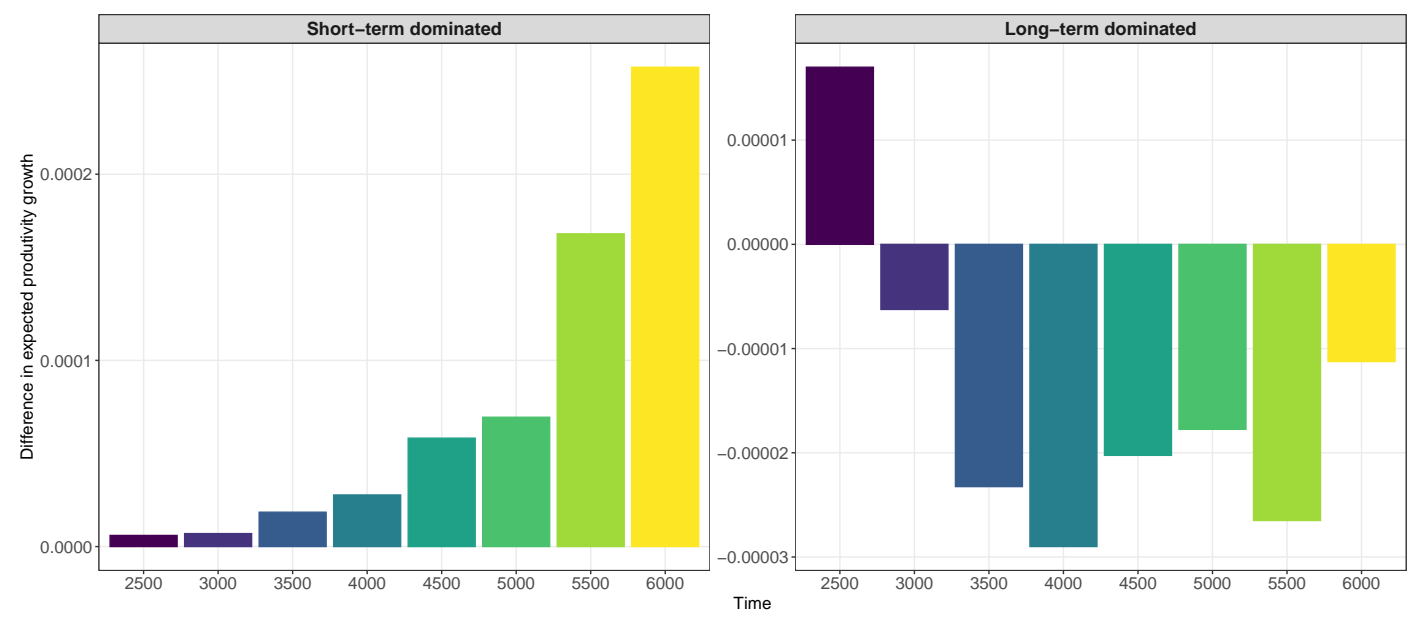

Figure 6: Difference in expected productivity growth between the market leader and the average of the first four following firms. Left: $\psi=0.1, \phi^{L}=0.09, \phi^{S}=0.81$. Right: $\psi=0.1, \phi^{L}=0.81, \phi^{S}=0.09$.

\subsubsection{The interaction between ownership structure and management payment schemes}

The results in the previous sections provide insights about how firm governance structure can shape industry dynamics. However, these results were conditional on a specific manager compensation scheme. However, Propositions 3 and 4 indicate that the weights of bonuses vs. stock-based payments in the manager's remuneration scheme (respectively $\gamma$ and $\beta$ in Equation (26)) affect the optimal investment profile of the firm. In our calibrated simulation analysis, we used $\gamma=0.01$ as the proportion of profits paid out as bonus and $\beta=1.6$ as the number of shares provided in each period to the manager as part of her remuneration. Our simulations suggest that, under this configuration, a manager has the incentive to favour real investments over buybacks.

We now take a broader perspective and we discuss experiments where we change the ratio between these two parameters by varying $\gamma \in\{0.001,0.01,0.1\}$ while keeping $\beta$ constant at the baseline level. A lower (higher) value of $\gamma$ decreases (increases) the fraction of profits paid out as bonus and therefore reduces (increases) the manager's incentives towards real investments. This setting allows us to analyse how the relationship between ownership structure and industry dynamics is mediated by the compensation scheme of the manager.

We first study effects of the above change in manager's remuneration on steady-state industry productivity growth. Figure 7 shows how the relationship between productivity growth and longterm investors changes with different levels of manager's bonuses: low ( $\gamma=0.001$, left panel), baseline $(\gamma=0.01$, middle panel), and high ( $\gamma=0.1$ right panel). The relationship is clearly affected by the manager's payment scheme. In particular, the result we highlighted in Section 6.1 about the neutrality of ownership structure on productivity growth with high manager's autonomy holds only if manager's remuneration is sufficiently bonus-based (respectively, baseline and high bonus scenarios in Figure 6.1 ). On the contrary, when manager's remuneration is mainly stock-based (low bonus scenario), increasing the share of long-term investors has a positive effect on productivity growth even with high manager's autonomy. This is explained by the fact that a higher weight of stocks in the manager's payment scheme increase her incentives towards share buybacks and hampers productivity growth. This harmful effect on productivity can be corrected by increasing the ownership 


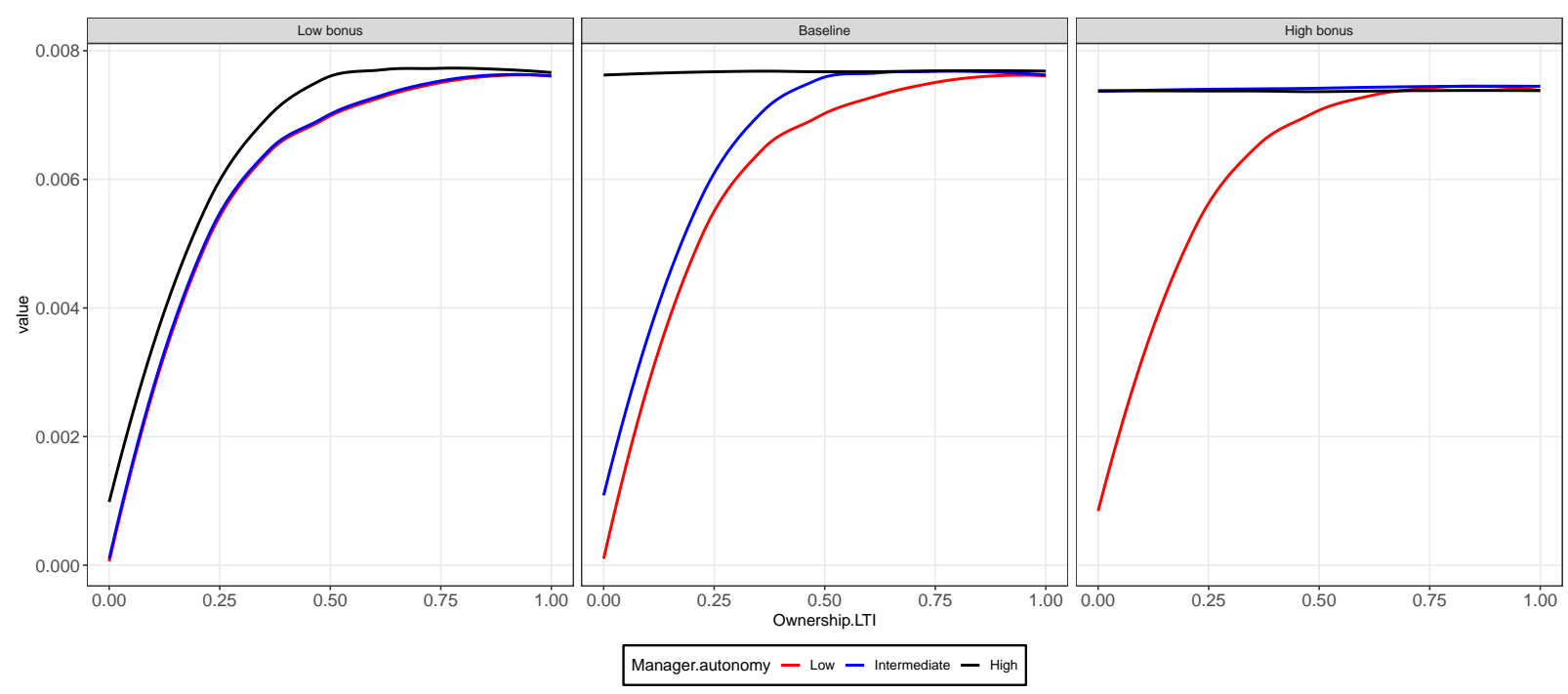

Figure 7: Spline-smoothed productivity growth as a function of the proportion of shares $\ell$ controlled by the long-term investors, evaluated for the different levels of the manager autonomy (red: $\psi=10 \%$; blue: $\psi=50 \%$; black: $\psi=90 \%$ ). The three plots are evaluated for different levels of bonus payments $\gamma$ (low bonus: $\gamma=0.001$; baseline: $\gamma=0.01$; high bonus: $\gamma=0.1)$.

share of long-term investors

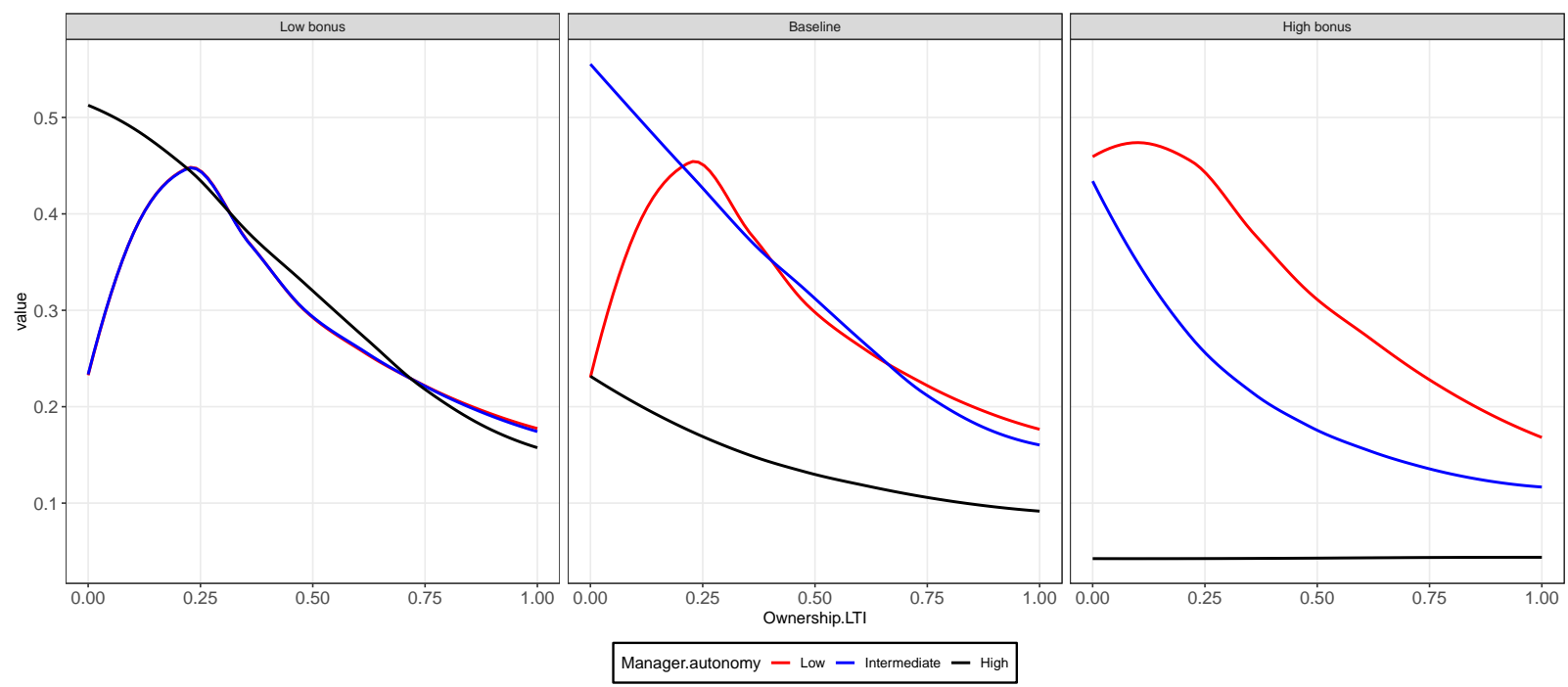

Figure 8: Spline-smoothed Herfindahl-Hirschman Index as a function of the proportion of shares $\ell$ controlled by the longterm investors, evaluated for the different levels of the manager autonomy (red: $\psi=10 \%$; blue: $\psi=50 \%$; black: $\psi=90 \%$ ). The three plots are evaluated for different levels of bonus payments $\gamma$ (low bonus: $\gamma=0.001$; baseline: $\gamma=0.01$; high bonus: $\gamma=0.1)$.

A similar analysis can be carried out for market concentration. Figure 8 displays the Herfindahl index in the governance structure space, for the same three levels of $\gamma \in\{0.001,0.01,0.1\}$. Increasing the bonus parameter $\gamma$, has the effect of flattening the relation between market concentration and the ownership share of long-term investors, especially when the degree of manager's autonomy is high (cf. the black spline in Figure Figure 8). In particular, we obtain that the distribution of ownership share is neutral with respect to market concentration and that market concentration is lowest when a manager is very independent from shareholders and her remuneration is mainly bonus-based (high bonus scenario). Manager's are shielded from shareholders influence in this scenario and in addition have strongest incentives towards $R \& D$. This will generate fierce technological competition among firms, which results into low level of concentration in the industry (and high productivity growth 
rates, see above discussion).

\subsubsection{The link between competition and innovation}

Let us take stock of the results obtained so far to investigate how the relation between innovation and competition is affected by governance structure. To this end, we consider a population of industries characterized by heterogeneous governance structures and heterogeneous manager remuneration schemes. We then analyse the combinations of productivity growth and concentration in a scatter plot at different life-cycle phases. In particular, we assume that the characteristics of these industries are equally distributed across the interval of manager's autonomy $\psi \in[0.1,0.9]$, the interval of proportions of shares held by long-term investor $\ell \in[0.1,0.9]$ and the three bonus parameters values $\gamma \in\{0.001,0.01,0.1\}$. By doing so, we exclude the extreme governance structures, i.e. those where one of the stakeholders exercises almost full control in the governance of the firm.

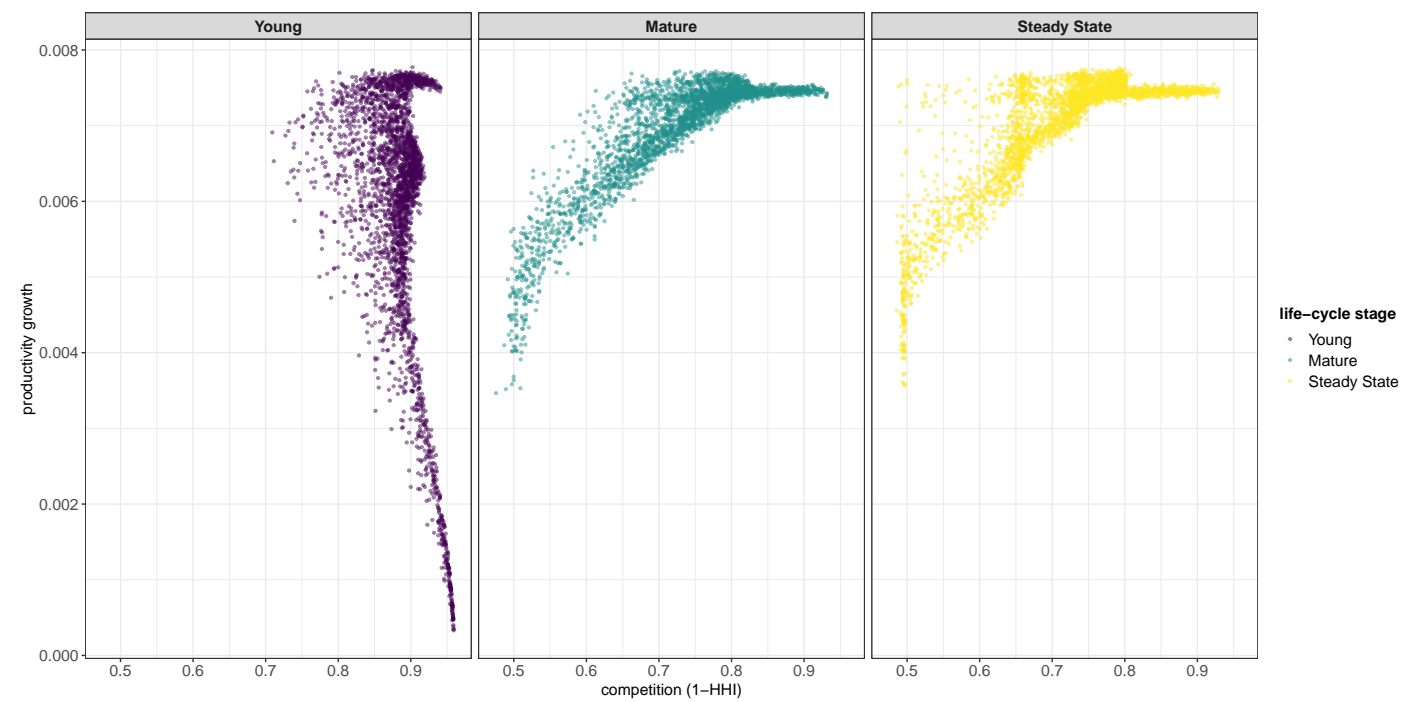

Figure 9: Scatter plots describing the relation between competition and productivity growth over the governance structure space. Each quadrant depicts the relation for a specific point in time.

Figure 9 provides three separate scatter plots showing the relation between innovation and competition and different stages of an industry life-cycle: young (left panel), mature (middle panel), steady state (right panel). In the figures we use the complement to one of the Herfindahl index as a measure for competition. Productivity growth measures instead innovation. The plots reveal that the relation between productivity growth and competition changes over an industry life-cycle. In the young phase of an industry evolution, the relation between innovation and competition is monotonically decreasing. It is instead monotonically increasing at a mature stage and in steady state. Notice also that the range of market concentration is different across life-cycle stages. It is much wider in the mature and steady state phase than in a young one. Finally, by pooling together the data for industries over different stages of industry evolution, one finds that the relation between competition and innovation has the empirically-documented inverted U-shaped shape (cfr. Aghion et al., 2005, and the discussion in Section 1).

Heterogeneous governance structures can explain these different patterns. Take the young stage first. Industries dominated by short-term investors are industries where firms favour share buybacks over R\&D. As a result, overall productivity growth is low but market concentration is also low because market selection and the process of firm differentiation through R\&D and productivity is very 
slow. Accordingly, no firm is able to get a significant lead in productivity and market share. At the other extreme, industries dominated by long-term investors are industries where firms put more effort in R\&D. This generates high aggregate productivity growth but also faster differentiation across firms and high market concentration.

Next, consider more mature stages of an industry. In short-term dominated industries, the few firms that have obtained some productivity gains, begin to have stronger incentives toward R\&D real investments (recall the left panel in Figure 6 and the discussion in Section 6.2). This allows them to increase their productivity growth and to eventually dominate the market while other firms remain stuck at low levels of productivity and market share. The result is that market concentration becomes high paired with an aggregate productivity growth that remains low. In long-term dominated industries, instead, $R \& D$ based competition remains fierce and continues to command high aggregate productivity growth rates. In addition, the technological leader eventually falls behind its neck-and-neck competitors and market concentration stabilizes (cf. Figure 6, right-panel and Section 6.2).

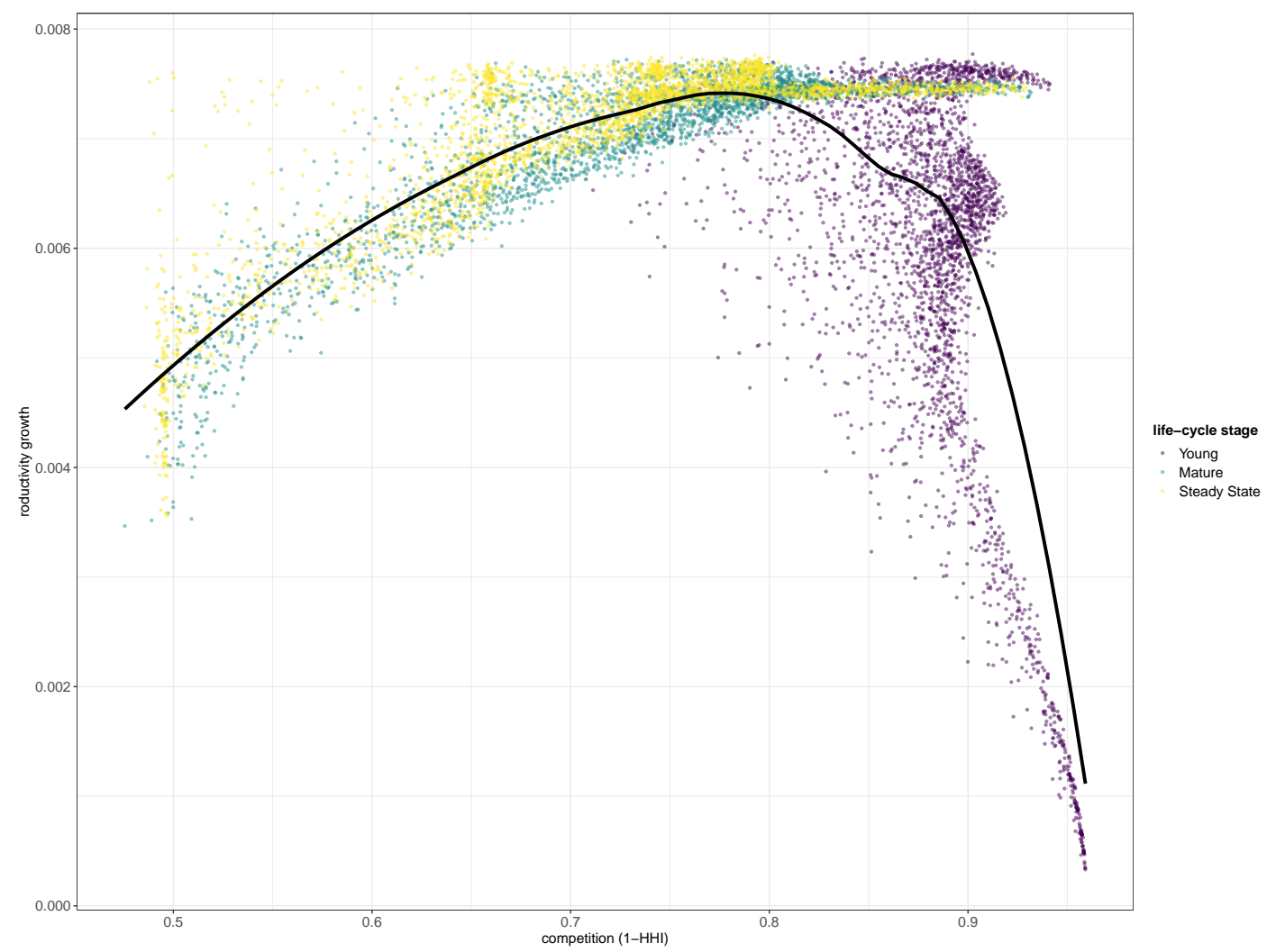

Figure 10: Spline-smoothed relation between competition measured as the market concentration and productivity growth, evaluated at fixed levels of the manager autonomy (red: $\psi=10 \%$; blue: $\psi=50 \%$; black: $\psi=90 \%$ ).

\section{Discussion and conclusion}

There has been a rise in the presence and active participation of different types of institutional investors for publicly listed firms over the past decades. Such a rise has had significant impact on the corporate governance landscape. At the same time, non-financial corporations have started to reallocate resources from real investments to financial activities that are not related to their core business. Share repurchase programs have played an important role in this context. 
In this paper, we analysed how these two trends might influence the pace of technical progress and the degree of industry competition. We developed a formal theory relating governance structure, stakeholders' incentives, and investment decisions within a firm. We showed that the model captures the stylized facts that a higher participation of short-term investors has a negative effect on $R \& D$ incentives whereas an increasing stock-based compensation of managers induces more share buybacks.

Next, we extended the model to a dynamic and stochastic framework, to study the non-trivial relationships between innovation and industry concentration. In general and in accordance with recent empirical evidence, we record an inverted-U shaped relation between these two variables. However, such a relationship could only be found by accounting for industries characterized by a wide range of governance structures and at different stages of the industry life-cycle.

Two transmission channels explain our results. First, we obtain a monotonically increasing relation between the proportion of shares controlled by long-term institutional investors and R\&Ddriven productivity growth. Second, we find an inverted-U shaped link between the ownership share of long-term investors and market concentration in the transitional dynamics of an industry. This inverted-U shaped relation is explained by leap-frogging versus pre-emption competition dynamics among firms, that are triggered by different governance structures.

Overall, our results put emphasis on the importance of taking corporate governance into account when analysing the link between innovation and competition. They also show that this relation may change significantly over the life-cycle of an industry. Finally, they suggest that the hump-shaped relation documented in the empirical literature can be the result of industries characterized by very different market selection dynamics.

From a policy perspective, the preferred situation is one wherein rapid technical change and high levels of competition are simultaneously achieved. Our analysis suggests that this is feasible only under specific conditions. First, a sufficient proportion of the shares must be controlled by investors with a long-term horizon. Second, and complementary to it, corporations should provide the right incentives for the management to prefer real investments over buybacks. This can be achieved by setting remuneration schemes that provide a strong link between stable corporate profitability and the salary of the managers. At the same time, the firm must provide managers with a substantial autonomy to lower the influence of short-term investors.

\section{Acknowledgments}

Mattia Guerini has received funding from the European Union's Horizon 2020 research and innovation programme under the Marie Sklodowska-Curie grant agreement No 799412 (ACEPOL). Philipp Harting and Mauro Napoletano acknowledge the financial support of the H2020 project "Growth Welfare Innovation Productivity" (GROWINPRO), grant agreement No 822781. We also gratefully acknowledge the Center for Parallel Computing at the University of Paderborn for providing us with computational resources on the OCULUS high-performance computing cluster. We are thankful to Uwe Cantner, Herbert Dawid, Maurizio Iacopetta, Lionel Nesta, Michael Neugart, Francesco Vona for helpful comments and to seminar participants at WEHIA, CEF, EAEPE 2019, and internal seminars at Bielefeld University, TU Darmstadt and OFCE. 


\section{References}

Aghion, P., N. Bloom, R. Blundell, R. Griffith, and P. Howitt (2005). Competition and innovation: an inverted-U relationship. The Quarterly Journal of Economics 120(2), 701-728.

Aghion, P., J. Van Reenen, and L. Zingales (2013). Innovation and institutional ownership. The American Economic Review 103(1), 277-304.

Askenazy, P., C. Cahn, and D. Irac (2013). Competition, R\&D, and the cost of innovation: evidence for France. Oxford Economic Papers 65(2), 293-311.

Bens, D. A., V. Nagar, and M. F. Wong (2002). Real investment implications of employee stock option exercises. Journal of Accounting Research 40(2), 359-393.

Bhargava, A. (2013). Executive compensation, share repurchases and investment expenditures: econometric evidence from US firms. Review of Quantitative Finance and Accounting 40(3), 403-422.

Bolton, P., J. Scheinkman, and W. Xiong (2006). Executive compensation and short-termist behaviour in speculative markets. The Review of Economic Studies 73(3), 577-610.

Brock, W. A. and C. H. Hommes (1998). Heterogeneous beliefs and routes to chaos in a simple asset pricing model. Journal of Economic Dynamics and Control 22(8), 1235 - 1274.

Brossard, O., S. Lavigne, and M. Erdem Sakinç (2013). Ownership structures and R\&D in Europe: the good institutional investors, the bad and ugly impatient shareholders. Industrial and Corporate Change 22(4), 1031-1068.

Bushee, B. J. (1998). The influence of institutional investors on myopic R\&D investment behavior. Accounting Review, 305-333.

Chakravarty, A. and R. Grewal (2011). The stock market in the driver's seat! Implications for R\&D and marketing. Management Science 57(9), 1594-1609.

Comment, R. and G. A. Jarrell (1991). The relative signalling power of dutch-auction and fixed-price self-tender offers and open-market share repurchases. The Journal of Finance 46(4), 1243-1271.

Cremers, M., A. Pareek, and Z. Sautner (2020). Short-term investors, long-term investments, and firm value: Evidence from russell 2000 index inclusions. Management Science (forthcoming).

Dawid, H., P. Harting, and S. van der Hoog (2019). Manager remuneration, share buybacks, and firm performance. Industrial and Corporate Change 28(3), 681-706.

Dittmar, A. K. (2000). Why do firms repurchase stock. The Journal of Business 73(3), 331-355.

Dosi, G. and Y. Kaniovski (1994, Jun). On “badly behaved” dynamics. Journal of Evolutionary Economics 4(2), 93-123.

Dosi, G., O. Marsili, L. Orsenigo, and R. Salvatore (1995). Learning, market selection and the evolution of industrial structures. Small Business Economics 7(6), 411-436.

Dosi, G., M. C. Pereira, and M. E. Virgillito (2017). The footprint of evolutionary processes of learning and selection upon the statistical properties of industrial dynamics. Industrial and Corporate Change 26(2), 187-210.

Epstein, G. A. (2005). Financialization and the World Economy. Edward Elgar Publishing.

Fudenberg, D., R. Gilbert, J. Stiglitz, and J. Tirole (1983). Preemption, leapfrogging and competition in patent races. European Economic Review 22(1), 3-31.

Gaspar, J.-M., M. Massa, P. Matos, R. Patgiri, and Z. Rehman (2012). Payout policy choices and shareholder investment horizons. Review of Finance 17(1), 261-320.

Gillan, S. L. and L. T. Starks (2007). The evolution of shareholder activism in the united states. Journal of Applied Corporate Finance 19(1), 55-73. 
Honoré, F., F. Munari, and B. v. P. de La Potterie (2015). Corporate governance practices and companies R\&D intensity: Evidence from european countries. Research policy 44(2), 533-543.

Ikenberry, D., J. Lakonishok, and T. Vermaelen (1995). Market underreaction to open market share repurchases. Journal of Financial Economics 39(2-3), 181-208.

Jäger, K. (2017). EU KLEMS growth and productivity accounts 2017 release - Description of methodology and general notes.

Jensen, M. C. and W. H. Meckling (1976). Theory of the firm: managerial behavior, agency costs and ownership structure. Journal of Financial Economics 3(4), 305 - 360.

Jovanovic, B. and G. M. MacDonald (1994). The life cycle of a competitive industry. Journal of Political Economy 102(2), 322-347.

Kilponen, J. and T. Santavirta (2007). When do R\&D subsidies boost innovation? Revisiting the inverted U-shape. Technical report, Bank of Finland.

Kim, H., H. Kim, and P. M. Lee (2008). Ownership structure and the relationship between financial slack and R\&D investments: Evidence from korean firms. Organization Science 19(3), 404-418.

Klepper, S. (1996). Entry, exit, growth, and innovation over the product life cycle. The American Economic Review 86(3), 562-583.

Krishna, V. and R. Serrano (1996). Multilateral bargaining. The Review of Economic Studies 63(1), 61-80.

Lazonick, W. (2014). Profits without prosperity. Harvard Business Review 92(9), 46-55.

Lazonick, W. and M. O'Sullivan (2000). Maximizing shareholder value: a new ideology for corporate governance. Economy and Society 29(1), 13-35.

Levin, R. C., W. M. Cohen, and D. C. Mowery (1985). R\&D appropriability, opportunity, and market structure: new evidence on some schumpeterian hypotheses. The American Economic Review 75(2), 20-24.

Peneder, M. and M. Wörter (2014). Competition, R\&D and innovation: testing the inverted-U in a simultaneous system. Journal of Evolutionary Economics 24(3), 653-687.

Polder, M. and E. Veldhuizen (2012). Innovation and competition in the Netherlands: Testing the inverted-U for industries and firms. Journal of Industry, Competition and Trade 12(1), 67-91.

Sakinc, M. E. (2017). Share repurchases in Europe. A value extraction analysis. ISIGrowth Working Paper Series (16).

Scherer, F. M. (1967). Market structure and the employment of scientists and engineers. The American Economic Review 57(3), 524-531.

Shailer, G. (2004). An Introduction to Corporate Governance in Australia. Pearson Education Australia, Sydney.

Sherman, H., S. Beldona, and M. Joshi (1998). Institutional investor heterogeneity: implications for strategic decisions. Corporate Governance: An International Review 6(3), 166-173.

Tingvall, P. G. and A. Poldahl (2006). Is there really an inverted U-shaped relation between competition and R\&D? Economics of Innovation and New Technology 15(2), 101-118.

Turco, E. M. (2018). Are stock buybacks crowding out real investment? Empirical evidence from US firms. Ph. D. thesis, Dissertation, University of Amsterdam, Amsterdam.

Walker, D. (2002). Managerial power and rent extraction in the design of executive compensation. The University of Chicago Law Review 69, 751.

Winter, S. G., Y. M. Kaniovski, and G. Dosi (2003). A baseline model of industry evolution. Journal of Evolutionary Economics 13(4), 355-383.

Young, M. N., M. W. Peng, D. Ahlstrom, G. D. Bruton, and Y. Jiang (2008). Corporate governance in emerging economies: a review of the principal - principal perspective. Journal of Management Studies 45(1), 196-220. 


\section{A Proofs}

Proof of Proposition 1. First we prove the first statement of the proposition, if $b^{*}$ is an interior solution, then i.e. $\frac{\partial b^{*}}{\partial \ell}<0$. The optimal $b^{*}$ can be derived from maximizing the logarithmic objective function $j(b)=\log J(b)$ which yields the first-order condition

$$
\frac{\partial j\left(b^{*}\right)}{\partial b^{*}}=\frac{\ell(\psi-1) \Pi^{\prime}\left(1-b^{*}\right)}{\Pi\left(1-b^{*}\right)}+\frac{(\ell-1)(\psi-1)\left((\gamma-1) q \Pi^{\prime}\left(1-b^{*}\right)+1\right)}{\Pi\left(1-b^{*}\right) q(1-\gamma)+b^{*}}+\frac{\psi\left(\beta-q \Pi^{\prime}\left(1-b^{*}\right)(\beta+\gamma n)\right)}{b^{*} \beta+q \Pi\left(1-b^{*}\right)(\beta+\gamma n)}=0 .
$$

At the same time the second-order condition has to hold in order to obtain a maximum, i.e.

$$
\frac{\partial^{2} j\left(b^{*}\right)}{\partial b^{2}}<0
$$

The marginal effect of $\ell$ on $b^{*}$ can be derived from the first-order condition by implicit differentiation. Writing the first-order condition as an implicit function $H\left(b^{*}, \ell\right)=0$, the marginal effect is then

$$
\frac{\partial b^{*}}{\partial \ell}=-\frac{\frac{\partial H\left(b^{*}, \ell\right)}{\partial \ell}}{\frac{\partial H\left(b^{*}, \ell\right)}{\partial b^{*}}} .
$$

Inserting the functional forms provided in Section 3 yields the following expression for the marginal effect:

$$
\frac{\partial b^{*}}{\partial \ell}=-\frac{(1-\psi)\left(b \Pi^{\prime}(1-b)+\Pi(1-b)\right)}{\Pi(1-b)((\gamma-1) q \Pi(1-b)-b)} \cdot\left(\frac{\partial H\left(b^{*}, \ell\right)}{\partial b^{*}}\right)^{-1} .
$$

Given the assumptions regarding $\Pi$, the parameter restrictions and the fact that $0<b^{*}<1$ as well as that the term $\frac{\partial H\left(b^{*}, \phi^{S}\right)}{\partial b^{*}}<0$ because of the second-order condition, it is $\frac{\partial b^{*}}{\partial \ell}<0$ and the first statement of the proposition follows.

If $b^{*}=b^{\max }$ and therefore a corner solution, we have to consider how the buyback cap $b^{\max }$ changes if $\ell$ changes. $b^{\max }$ is determined by the implicit function

$$
(1-\ell) \frac{q(1-\gamma) \Pi\left(1-b^{\max }\right)}{\ell}-b^{\max }=0
$$

Implicit differentiation yields

$$
\frac{\partial b^{\max }}{\partial \ell}=\frac{(\gamma-1) q \Pi\left(1-b^{\max }\right)}{\ell\left((\gamma-1)(\ell-1) q \Pi^{\prime}\left(1-b^{\max }\right)+\ell\right)}<0
$$

such that the second statement of the proposition follows.

Proof of Proposition 2. Similar to the proof of Proposition 1 we derive for the interior solution the marginal effect from the first-order condition by implicit differentiation. Writing the first-order condition by $H\left(b^{*}, \psi\right)=0$, the marginal effect is

$$
\frac{\partial b^{*}}{\partial \psi}=-\frac{\frac{\partial H\left(b^{*}, \psi\right)}{\partial \psi}}{\frac{\partial H\left(b^{*}, \psi\right)}{\partial b^{*}}},
$$

with

$$
\frac{\partial H\left(b^{*}, \psi\right)}{\partial \psi}=\frac{l \Pi^{\prime}\left(1-b^{*}\right)}{\Pi\left(1-b^{*}\right)}+\frac{(l-1)\left((\gamma-1) q \Pi^{\prime}\left(1-b^{*}\right)+1\right)}{\Pi\left(1-b^{*}\right)(q-\gamma q)+b^{*}}+\frac{\beta-q \Pi^{\prime}\left(1-b^{*}\right)(\beta+\gamma n)}{b^{*} \beta+q \Pi\left(1-b^{*}\right)(\beta+\gamma n)}
$$

and because of the second-order condition

$$
\frac{\partial H\left(b^{*}, \psi\right)}{\partial b^{*}}<0
$$

Given the parameter restrictions, it can be shown that:

1.

$$
\lim _{\gamma \rightarrow 0} \frac{\partial H\left(b^{*}, \psi\right)}{\partial \psi}=\frac{\ell\left(b^{*} \Pi^{\prime}\left(1-b^{*}\right)+\Pi\left(1-b^{*}\right)\right)}{\Pi\left(1-b^{*}\right)\left(q \Pi\left(1-b^{*}\right)+b^{*}\right)}>0,
$$

2.

$$
q\left(b^{*} \Pi^{\prime}\left(1-b^{*}\right)+\Pi\left(1-b^{*}\right)\right)\left(\frac{\ell-1}{\left(\Pi\left(1-b^{*}\right)(q-\gamma q)+b^{*}\right)^{2}}-\frac{\beta n}{\left(b^{*} \beta+q \Pi\left(1-b^{*}\right)(\beta+\gamma n)\right)^{2}}\right)<0 .
$$

Thus, if there is a $\tilde{\gamma} \in(0,1)$ solving $\frac{\partial H\left(b^{*}, \psi\right)}{\partial \psi}=0$, then $\frac{\partial b^{*}}{\partial \psi} \gtreqless 0$ if $\gamma \lesseqgtr \tilde{\gamma}$. Let $\gamma_{0}^{+} \in \mathbb{R}_{+}$solve $\frac{\partial H\left(b^{*}, \psi\right)}{\partial \psi}=0$ with

$$
\gamma_{0}^{+}=\frac{\beta \ell\left(q \Pi\left(1-b^{*}\right)+b^{*}\right)}{q \Pi\left(1-b^{*}\right)(\beta+n(1-\ell))}>0 .
$$

Then

$$
\gamma_{0}^{+}<1 \Leftrightarrow \beta<\frac{(1-\ell) n q \Pi\left(1-b^{*}\right)}{(\ell-1) q \Pi\left(1-b^{*}\right)+b^{*} \ell} .
$$


Thus, we define $\tilde{\gamma}=\frac{\beta \ell\left(q \Pi\left(1-b^{*}\right)+b^{*}\right)}{q \Pi\left(1-b^{*}\right)(\beta+n(1-\ell))}$ and $\tilde{\beta}=\max \left[0, \frac{(1-\ell) n q \Pi\left(1-b^{*}\right)}{(\ell-1) q \Pi\left(1-b^{*}\right)+b^{*} \ell}\right]$ and the first statement of the proposition follows.

The second statement of the proposition is trivial, since

$$
(1-\ell) \frac{q(1-\gamma) \Pi\left(1-b^{\max }\right)}{\ell}=b^{\max }
$$

does not depend on $\psi$.

Proof of Proposition 3. Similar to the proof of Proposition 1 we derive for the interior solution the marginal effect from the first-order condition by implicit differentiation. Writing the first-order condition by $H\left(b^{*}, \beta\right)=0$, the marginal effect is

$$
\frac{\partial b^{*}}{\partial \beta}=-\frac{\frac{\partial H\left(b^{*}, \beta\right)}{\partial \beta}}{\frac{\partial H\left(b^{*}, \beta\right)}{\partial b^{*}}}
$$

Given the parameter restrictions, we have

$$
\frac{\partial H\left(b^{*}, \beta\right)}{\partial \beta}=\frac{\gamma n q\left(b^{*} \Pi^{\prime}\left(1-b^{*}\right)+\Pi\left(1-b^{*}\right)\right)}{\left(b^{*} \beta+q \Pi\left(1-b^{*}\right)(\beta+\gamma n)\right)^{2}}>0
$$

and, from the second-order condition, we know that

$$
\frac{\partial H\left(b^{*}, \beta\right)}{\partial b^{*}}<0
$$

and the first statement of the proposition follows.

The second statement follows from the fact that

$$
(1-\ell) \frac{q(1-\gamma) \Pi\left(1-b^{\max }\right)}{\ell}-b^{\max }=0
$$

does not depend on $\beta$.

Proof of Proposition 4. Similar to the proof of Proposition 1 we derive for the interior solution the marginal effect from the first-order condition by implicit differentiation. Writing the first-order condition by $H\left(b^{*}, \gamma\right)=0$, the marginal effect is

$$
\frac{\partial b^{*}}{\partial \gamma}=-\frac{\frac{\partial H\left(b^{*}, \gamma\right)}{\partial \gamma}}{\frac{\partial H\left(b^{*}, \gamma\right)}{\partial b^{*}}}
$$

with

$$
\frac{\partial H\left(b^{*}, \gamma\right)}{\partial \gamma}=q\left(b^{*} \Pi^{\prime}\left(1-b^{*}\right)+\Pi\left(1-b^{*}\right)\right)\left(\frac{(\ell-1)(\psi-1)}{\left(\Pi\left(1-b^{*}\right)(q-\gamma q)+b^{*}\right)^{2}}-\frac{\beta n \psi}{\left(b^{*} \beta+q \Pi\left(1-b^{*}\right)(\beta+\gamma n)\right)^{2}}\right)
$$

and because of the second-order condition

$$
\frac{\partial H\left(b^{*}, \gamma\right)}{\partial b^{*}}<0
$$

Given the parameter restrictions, it can be shown that:

1.

$$
\lim _{\gamma \rightarrow 0} \frac{\partial H\left(b^{*}, \gamma\right)}{\partial \gamma}=\frac{q\left(b^{*} \Pi^{\prime}\left(1-b^{*}\right)+\Pi\left(1-b^{*}\right)\right)(\beta(\ell-1)(\psi-1)-n \psi)}{\beta\left(q \Pi\left(1-b^{*}\right)+b^{*}\right)^{2}}<0 \Leftrightarrow \beta<\frac{n \psi}{(1-\ell)(1-\psi)},
$$

2.

$$
\frac{\partial^{2} H\left(b^{*}, \gamma\right)}{\partial \gamma^{2}}=2 q^{2} \Pi\left(1-b^{*}\right)\left(b^{*} \Pi^{\prime}\left(1-b^{*}\right)+\Pi\left(1-b^{*}\right)\right)\left(\frac{(\ell-1)(\psi-1)}{\left(\Pi\left(1-b^{*}\right)(q-\gamma q)+b^{*}\right)^{3}}+\frac{\beta n^{2} \psi}{\left(b^{*} \beta+q \Pi\left(1-b^{*}\right)(\beta+\gamma n)\right)^{3}}\right)>0 .
$$

Thus, if $\beta \geq \frac{n \psi}{(1-\ell)(1-\psi)}$, then $\frac{\partial H\left(b^{*}, \gamma\right)}{\partial \gamma}>0 \forall \gamma \in(0,1)$. If, however, $\beta<\frac{n \psi}{(1-\ell)(1-\psi)}$, then it exists a positive root $0<\hat{\gamma}_{0}^{+}<1$ with

$$
\hat{\gamma}_{0}^{+}=\frac{\left(q \Pi\left(1-b^{*}\right)+b^{*}\right)\left(1-\beta q \sqrt{\frac{(\ell-1)(\psi-1)}{\beta n \psi}}\right)}{q \Pi\left(1-b^{*}\right)\left(n q \sqrt{\frac{(\ell-1)(\psi-1)}{\beta n \psi}}+1\right)}
$$

solving

$$
\frac{\partial H\left(b^{*}, \hat{\gamma}_{0}^{+}\right)}{\partial \gamma}=0
$$


Defining $\hat{\gamma}=\hat{\gamma}_{0}^{+}$, we have for $\beta<\frac{n \psi}{(1-\ell)(1-\psi)}$ that $\frac{\partial H\left(b^{*}, \gamma\right)}{\partial \gamma} \gtreqless 0 \Leftrightarrow \gamma \gtreqless \hat{\gamma}$ and the first statement of the proposition follows. For the second statement, by implicit differentiation of

$$
(1-\ell) \frac{q(1-\gamma) \Pi\left(1-b^{\max }\right)}{\ell}-b^{\max }=0 .
$$

with respect to $\gamma$ we obtain

$$
\frac{\partial b^{\max }}{\partial \gamma}=\frac{(\ell-1) q \Pi\left(1-b^{\max }\right)}{(\gamma-1)(\ell-1) q \Pi^{\prime}\left(1-b^{\max }\right)+\ell}<0,
$$

which proves the second statement of the proposition. 


\section{B Financial market clearing condition}

Following equations 21, 23 and 22, the market clearing condition for the financial market reads

$$
\begin{aligned}
& S \theta\left[\frac{\hat{d}_{i, t+1}+\hat{V}_{o, i, t+1}-(1+r) V_{i, t}}{\tilde{a} \hat{\sigma}_{i, t}^{2}}-\iota_{o, i, t-1}\right]+ \\
+ & S(1-\theta)\left[\frac{\hat{d}_{i, t+1}+\hat{V}_{p, i, t+1}-(1+r) V_{i, t}}{\tilde{a} \hat{\sigma}_{i, t}^{2}}-\iota_{p, i, t-1}\right]+ \\
- & \iota_{m, i, t-1}+\frac{B_{i, t}}{V_{i, t}}+\ell \cdot\left(N_{t}-\frac{B_{i, t}}{V_{i, t}}\right)-N_{i, t-1}^{L}=0,
\end{aligned}
$$

where $\iota_{h, i, t-1}$ is the number of shares held by optimists $(h=o)$, by pessimists $(h=p)$ or by the manager $(h=m)$ in the previous period. Note that $S \cdot \theta \iota_{o, i, t-1}+S(1-\theta) \iota_{p, i, t-1}+\iota_{m, i, t-1}+N_{i, t-1}^{L}$ is equal to $N_{i, t-1}$. Furthermore, let us write $a=\tilde{a} / S$. Then, we obtain

$$
\frac{\hat{d}_{i, t+1}-(1+r) V_{i, t}+V_{i, t-1}\left(1+\left[\theta \kappa_{o}+(1-\theta) \kappa_{p}\right] \frac{B_{i, t}}{V_{i, t} N_{i, t}}\right)}{a \hat{\sigma}_{i, t}^{2}}-N_{i, t}(1-\ell)+\frac{B_{i, t}}{V_{i, t}}(1+\ell)=0 .
$$

Rearranging the terms, this yields to the quadratic equation

$$
\begin{aligned}
(1+r) V_{i, t}^{2} & -\left(\hat{d}_{i, t+1}+V_{i, t-1}-(1-\ell) N_{i, t} a \hat{\sigma}_{i, t}^{2}\right) V_{i, t}+ \\
& -B_{i, t}\left(\frac{\left[\theta \kappa_{o}+(1-\theta) \kappa_{p}\right] V_{i, t-1}}{N_{i, t}}+(1+\ell) \cdot a \hat{\sigma}_{i, t}^{2}\right)=0 .
\end{aligned}
$$

Solving for the market clearing price and considering only the positive root of this quadratic equation leads to the determination of $V_{i, t}^{*}$ described by equation 24 . 


\section{Derivation of the optimal choice}

By separately computing the first order conditions for each stakeholder, we find that ${ }^{21}$

Manager

$$
\begin{aligned}
& \frac{\partial \mathcal{M}_{t}}{\partial I_{t}}=\gamma\left[\frac{\partial \Pi_{t}^{*}}{\partial I_{t}}\right] \\
& \frac{\partial \mathcal{M}_{t}}{\partial B_{t}}=\max \left[0, \beta \frac{\partial V_{t}}{\partial B_{t}}\right]
\end{aligned}
$$

Short-term investors

$$
\begin{aligned}
\frac{\partial \mathcal{S}_{t}}{\partial I_{t}} & =0 \\
\frac{\partial \mathcal{S}_{t}}{\partial B_{t}} & =N_{i, t}^{S} \cdot \max \left[0, \frac{\partial V_{t}}{\partial B_{t}}\right]
\end{aligned}
$$

Long-term investors

$$
\begin{aligned}
\frac{\partial \mathcal{L}_{t}}{\partial I_{t}} & =N_{i, t}^{L} \frac{\partial \hat{d}_{t+1}^{L}}{\partial I_{t}} \\
\frac{\partial \mathcal{L}_{t}}{\partial B_{t}} & =N_{i, t}^{L} \frac{\partial \hat{d}_{t+1}^{L}}{\partial B_{t}}+\hat{d}_{i, t+1}^{L} \frac{\partial N_{i, t}^{L}}{\partial B_{t}}+N_{i, t-1}^{L} \frac{\partial V_{t}}{\partial B_{t}}
\end{aligned}
$$

Notice that, in the the FOCs for manager, short- and long-term investors we have made use of the following expressions:

$$
\begin{aligned}
\frac{\partial \Pi_{i, t}^{*}}{\partial I_{i, t}} & =\frac{\alpha \lambda \tau \Delta \Pi_{i, t}}{R D_{i, t}^{\tau}} \exp \left\{-\lambda R D_{i, t}^{\tau}\right\} \\
\frac{\partial V_{i, t}}{\partial B_{i, t}} & =\frac{X_{2, i, t}}{\sqrt{X_{1, t, i}^{2}+4(1+r) X_{2, i, t} B_{i, t}}} \\
\frac{\partial \hat{d}_{i, t+1}^{L}}{\partial I_{i, t}} & =\frac{\delta(1+r)(1-\gamma) \frac{\partial \Pi_{i, t}^{*}}{\partial I_{i, t}}}{N_{i, t}+\beta-\frac{B_{i, t}}{V_{i, t}}} \\
\frac{\partial \hat{d}_{i, t+1}^{L}}{\partial B_{i, t}} & =\frac{\left(V_{i, t}-B_{i, t} \frac{\partial V_{i, t}}{\partial B_{i, t}}\right) \frac{D_{i, t+1}}{V_{i, t}}}{\left(N_{i, t}+\beta-\frac{B_{i, t}}{V_{i, t}}\right)^{2}} \\
\frac{\partial N_{i, t}^{L}}{\partial B_{i, t}} & =-\ell \cdot \frac{V_{i, t}-\frac{\partial V_{i, t}}{\partial B_{i, t}} N_{i, t}^{L}}{V_{i, t}^{2}} \\
D_{i, t+1} & =\delta(1+r)(1-\gamma) \Pi_{i, t}^{*}
\end{aligned}
$$

and that, in order to determine $\frac{d \Pi_{i, t}^{*}}{d I_{i, t}}$, we have defined the expected change in the market profit - by adopting the relation between investment and probability for having a successful innovation - as:

$$
\Delta \Pi_{i, t}=\Pi_{i, t}^{*}\left(\zeta_{i, t} A_{i, t-1}, \bar{g}_{t} \cdot \mathbf{A}_{-i, t}\right)-\Pi_{i, t}^{*}\left(A_{i, t-1}, \bar{g}_{t} \cdot \mathbf{A}_{-i, t}\right) .
$$

Here $\mathbf{A}_{-i, t}$ denotes the productivity vector of firm i's competitors and $\bar{g}_{t}$ is the average productivity growth observed over the last periods.

\footnotetext{
${ }^{21}$ In the following set of equations we omit the $i$ for notation brevity and clarity. For all the firms indeed, the problem to be solved is the same.
} 


\section{Benchmark parametrization}

\begin{tabular}{|c|c|c|}
\hline Symbol & Name & Value \\
\hline \multicolumn{3}{|c|}{ Industry Parameters } \\
\hline$n$ & Number of firms & 25 \\
\hline$r$ & Interest rate & 0.003 \\
\hline$\rho$ & Elasticity of substitution & 0.82 \\
\hline$\varphi$ & Wage adjustment parameter & 0.8 \\
\hline \multicolumn{3}{|c|}{ Firms Parameters } \\
\hline$\psi$ & Manager bargaining power & 0.333 \\
\hline$\ell$ & Fraction of shares controlled by founders & 0.4 \\
\hline$\zeta$ & Productivity growth factor & 1.004 \\
\hline$\mu$ & Mark-up on unit costs & 0.2 \\
\hline$\alpha$ & Max. innovation probability & 0.6 \\
\hline$\tau$ & R\&D intensity returns to scale & 0.65 \\
\hline$\lambda$ & R\&D effectiveness & 10.0 \\
\hline$W^{F}$ & Manager fix salary & 0.03 \\
\hline$\gamma$ & Manager share of profits & 0.01 \\
\hline$\beta$ & Managers shares per period & 1.6 \\
\hline \multicolumn{3}{|c|}{ Financial Market Parameters } \\
\hline$S$ & Number of short-term investors per firm & 10000 \\
\hline$\eta$ & Fraction optimists & 0.65 \\
\hline$\kappa_{O}$ & Impact factor optimists & 0.2 \\
\hline$\kappa_{p}$ & Impact factor pessimists & -0.1 \\
\hline$\tilde{a}$ & CARA coefficient & 0.1 \\
\hline$\tilde{\sigma}$ & CARA sd coefficient & 0.5 \\
\hline$\delta$ & Dividend ratio & 0.68 \\
\hline$\phi$ & Dividend expectation persistence & 0.5 \\
\hline \multicolumn{3}{|c|}{ Initial Conditions } \\
\hline$A_{i, 0}$ & Firm productivity & 1.0 \\
\hline$N_{i, 0}$ & Number of shares & 10000 \\
\hline$V_{i, 0}$ & Share price & 0.005 \\
\hline$w_{0}$ & Wage of workers & 1.0 \\
\hline$H H I_{0}$ & Herfindahl-Hirshman Index & 0.04 \\
\hline
\end{tabular}

Table 2: Calibrated parametrization and initial conditions. 


\section{ABOUT OFCE}

The Paris-based Observatoire français des conjonctures économiques (OFCE), or French Economic Observatory is an independent and publicly-funded centre whose activities focus on economic research, forecasting and the evaluation of public policy.

Its 1981 founding charter established it as part of the French Fondation nationale des sciences politiques (Sciences Po), and gave it the mission is to "ensure that the fruits of scientific rigour and academic independence serve the public debate about the economy". The OFCE fulfils this mission by conducting theoretical and empirical studies, taking part in international scientific networks, and assuring a regular presence in the media through close cooperation with the French and European public authorities. The work of the OFCE covers most fields of economic analysis, from macroeconomics, growth, social welfare programmes, taxation and employment policy to sustainable development, competition, innovation and regulatory affairs.

\section{ABOUT SCIENCES PO}

Sciences $\mathrm{Po}$ is an institution of higher education and research in the humanities and social sciences. Its work in law, economics, history, political science and sociology is pursued through ten research units and several crosscutting programmes.

Its research community includes over two hundred twenty members and three hundred fifty PhD candidates. Recognized internationally, their work covers a wide range of topics including education, democracies, urban development, globalization and public health.

One of Sciences Po's key objectives is to make a significant contribution to methodological, epistemological and theoretical advances in the humanities and social sciences. Sciences Po's mission is also to share the results of its research with the international research community, students, and more broadly, society as a whole. 